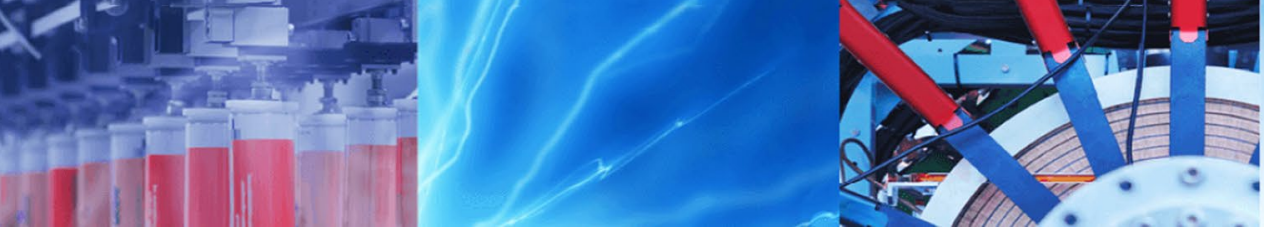

Research Article

\title{
Three oversampling methods applied in a comparative landslide spatial research in Penang Island, Malaysia
}

\author{
Han Gao ${ }^{1} \cdot$ Pei Shan Fam ${ }^{1} \cdot$ Lea Tien Tay ${ }^{2} \cdot$ Heng Chin Low ${ }^{3}$
}

Received: 9 March 2020 / Accepted: 6 August 2020 / Published online: 14 August 2020

(c) Springer Nature Switzerland AG 2020

\begin{abstract}
Two main problems in landslide spatial prediction research are the lack of landslide samples (minority) to train the models and the misunderstanding of assigning equal costs to different misclassifications. In order to handle the problems properly, the research is conducted based on two main objectives, which are to augment the landslide sample data in an efficient way and to assign proper unequal costs to the two types of error when training and evaluating models. Resampling techniques, including random oversampling technique, synthetic minority oversampling technique and self-creating oversampling technique (SCOTE), are used to augment the minority class samples. Logistic regression (LR) and support vector machine (SVM) are used for landslide spatial classification. Receiver operating characteristic and cost curves are used to evaluate the models. The results show that the SVM models trained using the dataset generated by SCOTE with sample size of 10,000 have the best prediction performance. The nonparametric test, Kruskal-Wallis test, is used to test the difference of sample size between different groups, which shows that LR models are more sensitive to the change of sample size. Two landslide susceptibility maps are produced based on the models with the best prediction performance. The verification results show that the maps both successfully predict more than $86 \%$ of the susceptible area, which can provide valid information on landslide mitigation and prediction to the local authorities.
\end{abstract}

Keywords Landslide susceptibility mapping · Wilcoxon rank-sum test · Cost curve $\cdot$ Self-creating oversampling $\cdot$ Support vector machine

\section{Introduction}

Landslides are a type of frequently occurred natural disaster, which can cause huge losses on life and property every year around the globe [24, 39]. Landslide susceptibility mapping (LSM) technique is a popular and powerful tool for landslide spatial assessment (LSA), which plays an essential role in landslide management and mitigation. A general problem in analyzing landslide data is the high imbalance ratio of non-landslide (majority) and landslide (minority) samples, which is an intrinsic problem to landslide spatial prediction domain [51]. In other words, the landslide samples of the raw data are rarely compared to the non-landslide samples. Generally, landslide data can provide more useful and valuable information than nonlandslide data for geological experts and data scientists when conducting LSA since the main objective of LSA is to predict the landslides successfully. However, non-landslide data are useful as well to avoid overfitting and a generalized overestimation of hazard. If the researchers select samples directly and randomly from the raw dataset, the problem of severe imbalance ratio probably occurs, which would highly deteriorate the models' prediction performance and further the LSM. Therefore, augmenting the

Pei Shan Fam, fpeishan@usm.my; Han Gao, alyssagaohan@gmail.com; Lea Tien Tay, tay@usm.my; Heng Chin Low, hclow@usm.my | 'School of Mathematical Sciences, Universiti Sains Malaysia (USM), 11800 Penang, Malaysia. ${ }^{2}$ School of Electrical and Electronic Engineering, USM, Engineering Campus, Seberang Perai Selatan, Nibong Tebal, 14300 Penang, Malaysia. ${ }^{3}$ Research and Innovation Unit, Universiti Sains Malaysia (USM), 11800 Penang, Malaysia. 
landslide data in an efficient way is a valuable research direction.

Resampling technique, more exactly oversampling, is considered to augment new landslide samples based on the raw landslide samples in this research. A total of three oversampling techniques, random oversampling technique (ROTE), synthetic minority oversampling technique (SMOTE) and self-creating oversampling technique (SCOTE), are used to augment the minority class samples. ROTE is a simple and commonly used way to generate 'new' samples through copying the old samples. SMOTE, proposed by Chawla et al. [11], generates new samples by interpolation. Wang et al. [51] applied SMOTE in a landslide susceptibility research and the results showed that SMOTE can improve the ML models' performances. SCOTE is a newly proposed method special for landslide data. The detailed information about SCOTE as well as the other two techniques is described in Sect. 3.2.2.

The exactness and effectiveness of LSM highly depend on the models or classifiers used in the research $[7,51]$. A wide range of models, including traditional statistical (TS) $[2,29,31,37]$ and machine learning $(\mathrm{ML})[12,36,55]$ models, are widely applied to produce landslide maps in recent decades. Other review papers on the methodology of LSM production are provided by Guzzetti et al. [23], Huabin et al. [26], Reichenbach et al. [45] and Gao et al. [21]. On the whole, ML models outperform the TS models [1, $10,38,41,53]$. Furthermore, based on the results of the previous researches, support vector machine (SVM) models, especially those with radial basis function (RBF) kernel, outperform other ML classification models [27, 33, 40, 42]. Logistic regression (LR) models showed powerful landslide prediction ability in various research as well $[4,8,18,22]$. The two aforementioned models, namely SVM and LR, would be applied to produce LSMs.

Model evaluation is of great importance when applying different ML models to produce LSMs. There are various metrics used to evaluate the model performance. The scalar metrics, such as accuracy, recall and precision, usually fail to provide comprehensive information for performance measure [20]. Since the prediction results obtained from ML models are usually continuous, a threshold value is needed when transforming the continuous value to a binary value. The selection to the threshold value would highly affect the results of performance measures.

Receiver operator characteristic (ROC) curve is being popular in evaluating the performance of landslide susceptibility models, because the threshold selection problem can be avoided by replacing the accuracy with area under the ROC curve (AUC) as the main metric for model evaluation [19]. Another problem in landslide model evaluation is the misclassification costs, namely false negatives and false positives, which are usually assumed to be equal.
However, the cost of a false negative is far higher than the cost of false positive in landslide prediction research. For example, predicting a non-landslide sample wrongly may waste some prevention cost only while predicting a landslide sample wrongly may cause severe damage to property and life. Cost curve is a performance measure which assigns unequal costs to different misclassifications. Besides that, a cost curve also considers the a priori probability, a probability that is derived purely by deductive reasoning [34], of the minority and majority samples. Frattini et al. [20] summarized the aforementioned model evaluation techniques of landslide susceptibility models.

The rest of the paper is organized as follows. A brief introduction of the study area as well as the available data is shown in Sect. 2. In Sect. 3, the methodology, including data preprocessing, resampling, modeling and performance measure methods, is described in detail. The results are displayed in Sect. 4 followed by the discussions in Sect. 5. In the discussions, several limitations of the research are introduced. Last but not least, the conclusions summarize the research in Sect. 6.

\section{Study area and data description}

Penang is one of the thirteen states in Malaysia. It has two parts: Penang Island and Seberang Perai. Only Penang Island is considered as our research area, since it has been heavily affected by landslides in recent decades due to frequent heavy rainfall. Penang Island is located in the northwest of Peninsular Malaysia. It is adjoined to the Malacca Strait, off the northwestern coast of Peninsular Malaysia, which is separated from the mainland by the Penang Strait. The digital elevation model (DEM) of Penang Island is displayed in Fig. 1.

Penang Island lies between $5^{\circ} 15^{\prime} \mathrm{N}$ and $5^{\circ} 30^{\prime} \mathrm{N}$, and $100^{\circ} 10^{\prime} \mathrm{E}$ and $100^{\circ} 20^{\prime} \mathrm{E}$, covering an area of $285 \mathrm{~km}^{2}$ [43]. Penang Island has a tropical rainforest climate with an average precipitation around $2477 \mathrm{~mm}$ annually and with the lowest being $60 \mathrm{~mm}$ in February, while the highest was around $210 \mathrm{~mm}$ between August and October annually. The annual temperatures range from 29 to $35^{\circ} \mathrm{C}$ during the day and from 26 to $29^{\circ} \mathrm{C}$ during the night (http://www. met.gov.my). The population of Penang Island is around 700,000 . The elevation varies from $0 \mathrm{~m}$ to $820 \mathrm{~m}$ above the sea level, while the highest point is Penang Hill. Based on the differences in mineralogy, texture and age, the granitic rocks in the study area can be categorized into two types, Sungai Ara and Bukit Bendera, which were named in local language [49]. The geology is composed mainly of Ferringhi granite, Batu Maung granite, clay and sand granite, which accounts for more than $70 \%$ of the study area [6]. Geologically, this area is underlain by a medium- to 
Fig. 1 The location of Penang Island

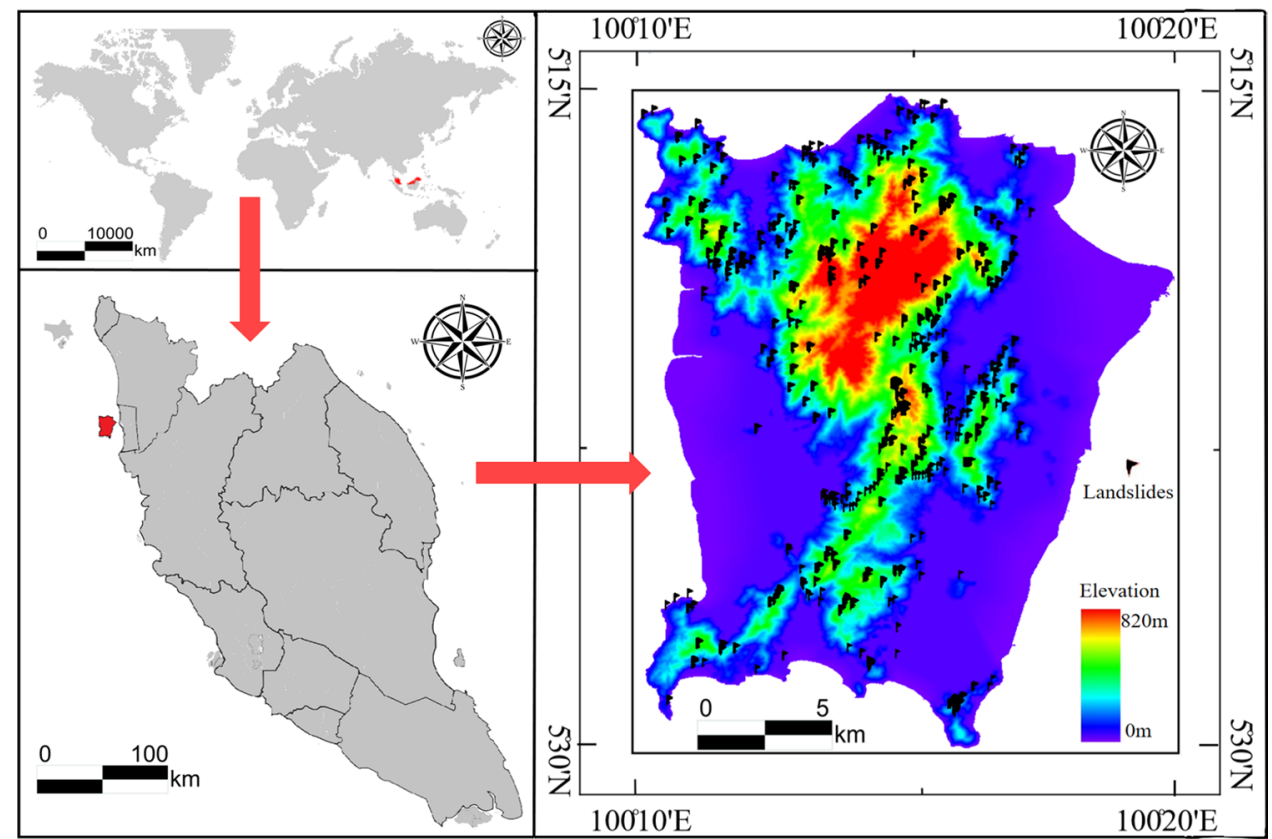

coarse-grained biotite granite layer with predominant orthoclase and subordinate microcline. The color of rock varies from light gray to dark gray, according to the amount of biotite present [5]. More detailed geological information can be found in the research by Ahmad et al. [3] and Pradhan and Lee [44].

A total of 382 past landslide occurrences (see Fig. 1) in Penang Island were collected from the landslide inventory database, GIS images and field survey conducted from 1995 to 2009. The smallest landslide covers around $300 \mathrm{~m}^{2}$, while the largest one covers around $39,800 \mathrm{~m}^{2}$. The average area of the 382 landslides is $5300 \mathrm{~m}^{2}$. According to the landslide classification system [50], the landslides that occurred in Penang Island can be classified as rotational slides, debris flows and rockfalls. The first two types of landslides account for more than $80 \%$ of all slides. We select a total of eleven landslide influencing factors, including six categorical (aspect, curvature, geology, soil type, landuse and rainfall) and five continuous (elevation, slope, distance to drainage, distance to road and distance to fault) variables. Table 1 displays the sources and formats of the available data. In order to have a complete picture of the data used in this research, the number, percentage as well as the frequency ratio of landslide pixels for each category of the eleven variables are displayed in Table 2 . The total number of pixels is $3,004,631$ each with the area of $10 \mathrm{~m}^{2}$. The calculation of frequency ratio is widely available in previous researches $[30,47]$. The bold fonts in the last column denote the categories with the largest $F R$ value for each variable, which indicates the largest importance of each category to some extent. Figure 2 displays the distribution of each landslide influencing factor.

Table 1 The sources and formats of the available data

\begin{tabular}{llll}
\hline Data & Format & Source & Purpose \\
\hline Landslide inventory & Polygon coverage & $\begin{array}{c}\text { Landslide inventory database, GIS images, } \\
\text { field survey }\end{array}$ & Landslide distribution \\
Topographic map & Line and point coverage & National mapping agency & Slope, aspect, curvature, elevation \\
Drainage map & Line coverage & Department of Agriculture & Distance from drainage \\
Soil map & Polygon coverage & Department of irrigation and drainage & Soil type \\
Landuse & GRID & Landsat TM images & Landuse \\
Precipitation & - & Malaysian Meteorological Department & Precipitation \\
Roads & Line coverage & - & Distance to roads \\
Geology map & Polygon coverage & Mineral and Geoscience Department & Distance to fault, geology \\
\hline
\end{tabular}


Table 2 The description of the landslide influencing factors

\begin{tabular}{|c|c|c|c|c|c|c|}
\hline Landslide influencing factor & Category & Pixels in domain & $\begin{array}{l}\% \text { of pixels in } \\
\text { domain@a }\end{array}$ & $\begin{array}{l}\text { No. of land- } \\
\text { slide pixels }\end{array}$ & $\begin{array}{l}\% \text { of landslide } \\
\text { pixels(b) }\end{array}$ & FR(b)/a) \\
\hline \multirow[t]{9}{*}{ Aspect } & Flat & $1,304,347$ & 43.411 & 649 & 3.206 & 0.074 \\
\hline & North & 200,605 & 6.677 & 2277 & 11.247 & 1.685 \\
\hline & Northeast & 245,556 & 8.173 & 3381 & 16.700 & 2.043 \\
\hline & East & 249,044 & 8.289 & 2712 & 13.396 & 1.616 \\
\hline & Southeast & 180,016 & 5.991 & 2158 & 10.659 & 1.779 \\
\hline & South & 196,646 & 6.545 & 2125 & 10.496 & 1.604 \\
\hline & Southwest & 226,837 & 7.550 & 2826 & 13.959 & 1.849 \\
\hline & West & 239,097 & 7.958 & 2585 & 12.769 & 1.605 \\
\hline & Northwest & 162,483 & 5.408 & 1532 & 7.567 & 1.399 \\
\hline \multirow[t]{3}{*}{ Curvature } & Convex & 747,908 & 24.892 & 10,523 & 51.978 & 2.088 \\
\hline & Concave & 793,313 & 26.403 & 8018 & 39.605 & 1.500 \\
\hline & Linear/flat & 1463,410 & 48.705 & 1704 & 8.417 & 0.173 \\
\hline \multirow[t]{6}{*}{ Soil type } & Sand & 33,339 & 1.110 & 0 & 0.000 & 0.000 \\
\hline & Sandy clay & 110,885 & 3.690 & 151 & 0.746 & 0.202 \\
\hline & Sandy clay loam & $1,632,926$ & 54.347 & 19,733 & 97.471 & 1.793 \\
\hline & Sandy loam & 401,268 & 13.355 & 239 & 1.181 & 0.088 \\
\hline & Silty clay & 82,924 & 2.760 & 18 & 0.089 & 0.032 \\
\hline & Urban land & 743,289 & 24.738 & 104 & 0.514 & 0.021 \\
\hline \multirow[t]{5}{*}{ Landuse/landcover } & Forest & $1,426,296$ & 47.470 & 14,134 & 69.815 & 1.471 \\
\hline & Vegetation & 399,591 & 13.299 & 3052 & 15.075 & 1.134 \\
\hline & Waterbody & 57,029 & 1.898 & 98 & 0.484 & 0.255 \\
\hline & Buildings & $1,087,729$ & 36.202 & 2817 & 13.915 & 0.384 \\
\hline & Hills & 33,986 & 1.131 & 144 & 0.711 & 0.629 \\
\hline \multirow[t]{9}{*}{ Precipitation (mm) } & $2254-2319.8$ & 21,266 & 0.708 & 268 & 1.324 & 1.870 \\
\hline & $2319.8-2379.3$ & 137,278 & 4.569 & 466 & 2.302 & 0.504 \\
\hline & $2379.3-2433.2$ & 371,750 & 12.373 & 3157 & 15.594 & 1.260 \\
\hline & 2433.2-2481.9 & 703,465 & 23.413 & 5007 & 24.732 & 1.056 \\
\hline & $2481.9-2535.8$ & 799,454 & 26.607 & 2021 & 9.983 & 0.375 \\
\hline & $2535.8-2595.8$ & 749,931 & 24.959 & 6658 & 32.887 & 1.318 \\
\hline & 2595.4-2661.1 & 140,010 & 4.660 & 1912 & 9.444 & 2.027 \\
\hline & $2661.1-2733.8$ & 56,951 & 1.895 & 505 & 2.494 & 1.316 \\
\hline & 2733.8-2903 & 24,526 & 0.816 & 251 & 1.240 & 1.519 \\
\hline \multirow[t]{8}{*}{ Elevation (m) } & $<80$ & $1,657,596$ & 55.168 & 3249 & 16.048 & 0.291 \\
\hline & $80-160$ & 347,651 & 11.571 & 3935 & 19.437 & 1.680 \\
\hline & $160-240$ & 295,573 & 9.837 & 3580 & 17.683 & 1.798 \\
\hline & $240-320$ & 221,230 & 7.363 & 2839 & 14.023 & 1.905 \\
\hline & $320-400$ & 151,870 & 5.055 & 2502 & 12.359 & 2.445 \\
\hline & $400-480$ & 112,132 & 3.732 & 1938 & 9.573 & 2.565 \\
\hline & $480-560$ & 98,015 & 3.262 & 1295 & 6.397 & 1.961 \\
\hline & $\geq 560$ & 120,564 & 4.013 & 907 & 4.480 & 1.117 \\
\hline \multirow[t]{6}{*}{ Geology } & Muka head microgranite & 43,388 & 1.444 & 418 & 2.065 & 1.430 \\
\hline & Feringgi granite & 585,307 & 19.480 & 6722 & 33.203 & 1.704 \\
\hline & Tanjung Bunga granite & 687,836 & 22.893 & 5663 & 27.972 & 1.222 \\
\hline & Sungai Ara granite & 79,690 & 2.652 & 159 & 0.785 & 0.296 \\
\hline & Batumaung granite & 838,988 & 27.923 & 7198 & 35.554 & 1.273 \\
\hline & Clay/sand/granite & 769,422 & 25.608 & 85 & 0.420 & 0.016 \\
\hline
\end{tabular}


Table 2 (continued)

\begin{tabular}{|c|c|c|c|c|c|c|}
\hline Landslide influencing factor & Category & Pixels in domain & $\begin{array}{l}\text { \% of pixels in } \\
\text { domain@ }\end{array}$ & $\begin{array}{l}\text { No. of land- } \\
\text { slide pixels }\end{array}$ & $\begin{array}{l}\% \text { of landslide } \\
\text { pixels(b) }\end{array}$ & FR(b)/@ \\
\hline \multirow[t]{7}{*}{ Slope $\left({ }^{\circ}\right)$} & $<8^{\circ}$ & $1,572,126$ & 52.323 & 1788 & 8.832 & 0.169 \\
\hline & $8-16$ & 383,768 & 12.773 & 3733 & 18.439 & 1.444 \\
\hline & $16-24$ & 503,229 & 16.748 & 5849 & 28.891 & 1.725 \\
\hline & $24-32$ & 373,725 & 12.438 & 5753 & 28.417 & 2.285 \\
\hline & $32-40$ & 136,969 & 4.559 & 2446 & 12.082 & 2.650 \\
\hline & $40-48$ & 28,794 & 0.958 & 533 & 2.633 & 2.747 \\
\hline & $\geq 48$ & 6020 & 0.200 & 143 & 0.706 & 3.525 \\
\hline \multirow[t]{10}{*}{ Distance to drainage (m) } & $<50 \mathrm{~m}$ & $1,065,235$ & 35.453 & 12,188 & 60.203 & 1.698 \\
\hline & $50-100$ & 551,895 & 18.368 & 3514 & 17.357 & 0.945 \\
\hline & $100-150$ & 370,501 & 12.331 & 2029 & 10.022 & 0.813 \\
\hline & 150-200 & 243,221 & 8.095 & 1223 & 6.041 & 0.746 \\
\hline & $200-250$ & 160,861 & 5.354 & 580 & 2.865 & 0.535 \\
\hline & $250-300$ & 112,740 & 3.752 & 292 & 1.442 & 0.384 \\
\hline & $300-350$ & 85,886 & 2.858 & 188 & 0.929 & 0.325 \\
\hline & $350-400$ & 68,610 & 2.283 & 157 & 0.776 & 0.340 \\
\hline & $400-450$ & 55,628 & 1.851 & 61 & 0.301 & 0.163 \\
\hline & $\geq 450$ & 290,054 & 9.654 & 13 & 0.064 & 0.007 \\
\hline \multirow[t]{11}{*}{ Distance to fault (m) } & $<100 \mathrm{~m}$ & 162,051 & 5.393 & 2068 & 10.215 & 1.894 \\
\hline & $100-200$ & 162,062 & 5.394 & 1013 & 5.004 & 0.928 \\
\hline & $200-300$ & 160,977 & 5.358 & 587 & 2.899 & 0.541 \\
\hline & $300-400$ & 159,440 & 5.306 & 1286 & 6.352 & 1.197 \\
\hline & $400-500$ & 157,227 & 5.233 & 1695 & 8.372 & 1.600 \\
\hline & $500-600$ & 152,441 & 5.074 & 1393 & 6.881 & 1.356 \\
\hline & $600-700$ & 147,331 & 4.903 & 1648 & 8.140 & 1.660 \\
\hline & $700-800$ & 137,526 & 4.577 & 1436 & 7.093 & 1.550 \\
\hline & $800-900$ & 127,240 & 4.235 & 1748 & 8.634 & 2.039 \\
\hline & $900-1000$ & 114,571 & 3.813 & 1068 & 5.275 & 1.383 \\
\hline & $\geq 1000$ & $1,523,765$ & 50.714 & 6303 & 31.134 & 0.614 \\
\hline \multirow[t]{10}{*}{ Distance to road (m) } & $<50 m$ & 955,518 & 31.802 & 1944 & 9.602 & 0.302 \\
\hline & $50-100$ & 259,649 & 8.642 & 612 & 3.023 & 0.350 \\
\hline & $100-150$ & 185,292 & 6.167 & 949 & 4.688 & 0.760 \\
\hline & $150-200$ & 148,444 & 4.941 & 903 & 4.460 & 0.903 \\
\hline & $200-250$ & 126,604 & 4.214 & 945 & 4.668 & 1.108 \\
\hline & $250-300$ & 109,318 & 3.638 & 980 & 4.841 & 1.330 \\
\hline & $300-350$ & 97,129 & 3.233 & 1104 & 5.453 & 1.687 \\
\hline & $350-400$ & 88,671 & 2.951 & 1217 & 6.011 & 2.037 \\
\hline & $400-450$ & 81,434 & 2.710 & 813 & 4.016 & 1.482 \\
\hline & $\geq 450$ & 952,572 & 31.703 & 10,778 & 53.238 & 1.679 \\
\hline
\end{tabular}

\section{Methodology}

\subsection{Data preprocessing}

Multicollinearity analysis is conducted before model training and validation. It refers to a linear association between two or more independent variables. It is highly important to determine the correlation of the influencing factors, since the models may fail to measure the contribution of each independent variable if multicollinearity occurs. Variance Inflation Factor (VIF) and Tolerance (Tol) are commonly used to evaluate the multicollinearity [35]. The formula of VIF is shown as:

$\mathrm{VIF}=1 /\left(1-R_{i}^{2}\right)$, 


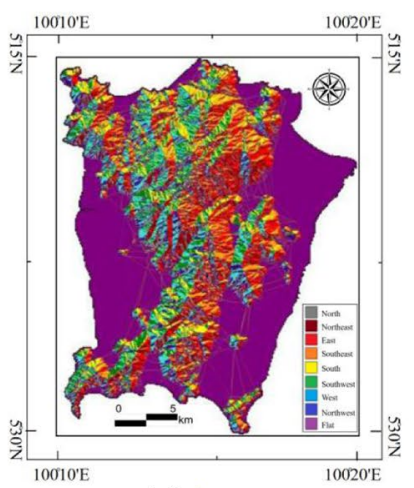

(a) Aspect

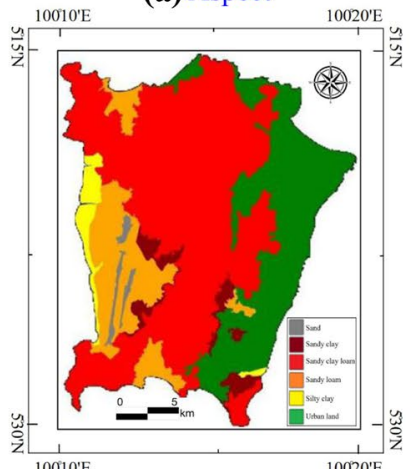

(d) Soil type

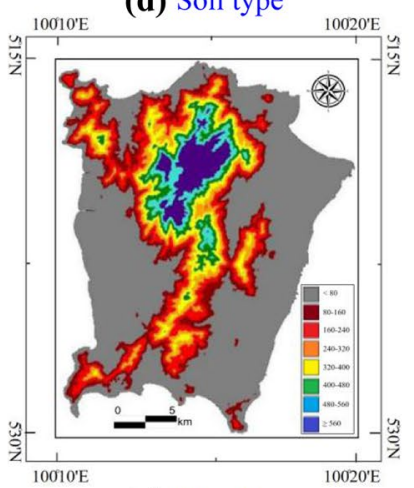

(g) Elevation

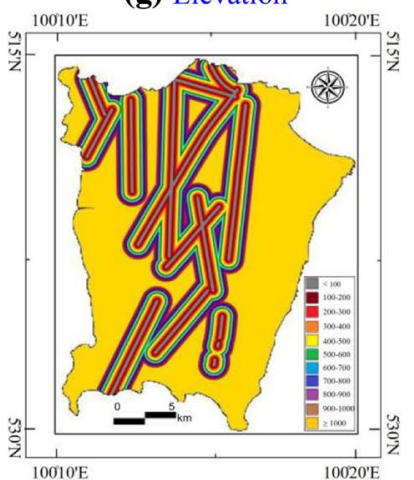

(j) Distance to fault

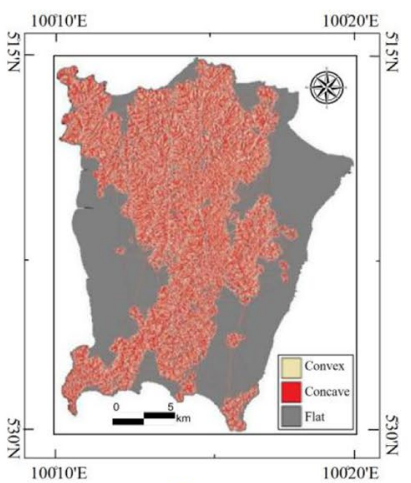

(b) Curvature

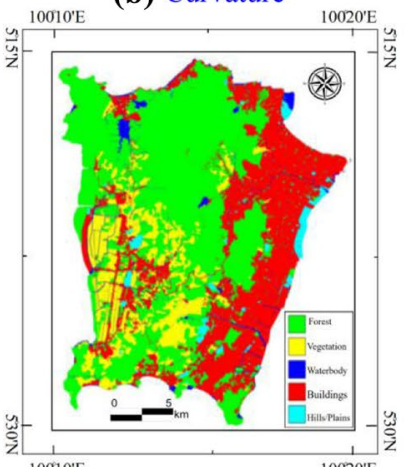

(e) Landuse

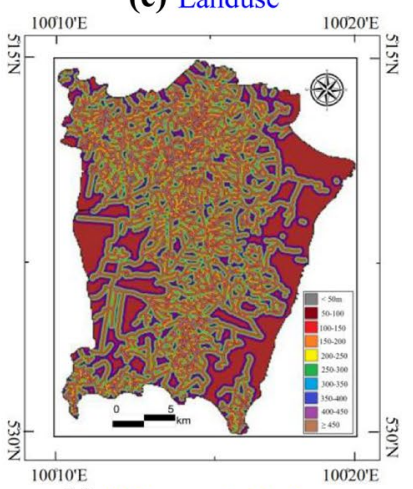

(h) Distance to drainage

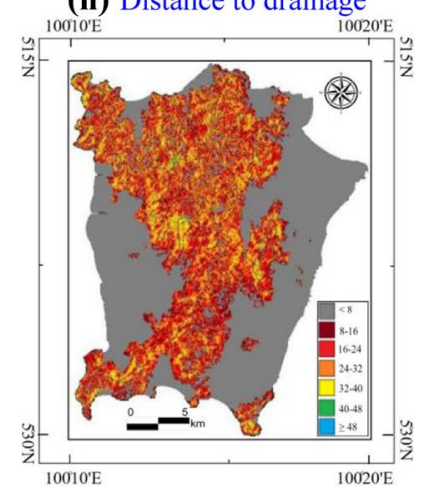

(k) Slope angle

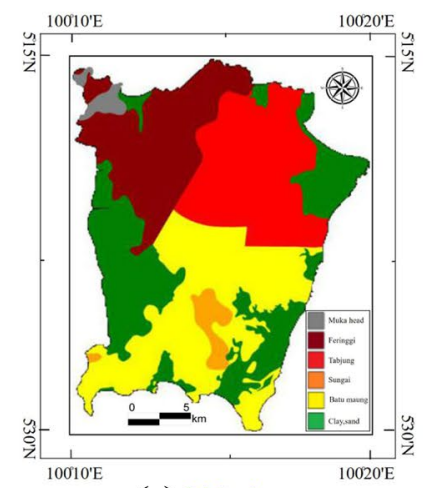

(c) Lithology

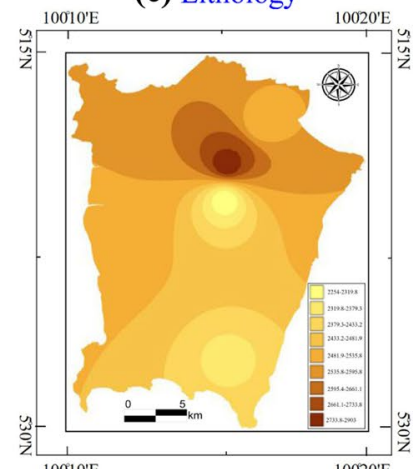

(f) Precipitation

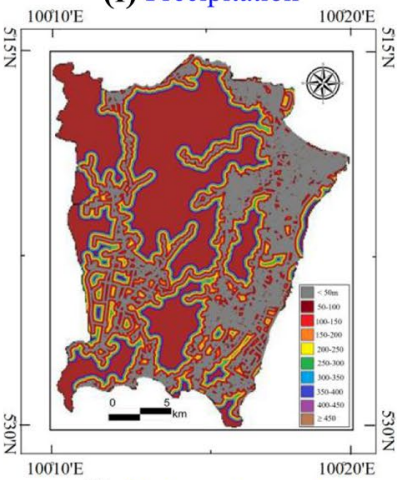

(i) Distance to road

Fig. 2 The eleven landslide influencing factors. a Aspect; $\mathbf{b}$ curvature; $\mathbf{c}$ lithology; $\mathbf{d}$ soil type; $\mathbf{e}$ landuse; $\mathbf{f}$ precipitation; $\mathbf{g}$ elevation; $\mathbf{h}$ distance to drainage; $\mathbf{i}$ distance to road; $\mathbf{j}$ distance to fault; $\mathbf{k}$ slope angle 
where the $R_{i}^{2}, i=1,2, \ldots$ denotes the coefficient of determination of the variable $i$ on all other variables. The value of Tol can be obtained by calculating the reciprocal of VIF value. When the VIF value of an influencing factor is larger than 5 or the Tol value is less than 0.2 , it indicates that the multicollinearity problem occurs and the factor should be removed from the model [34].

Moreover, the importance of each landslide influencing factor is measured by random forest (RF) technique $[28,46]$. It was first proposed by Ho [25]. The fundamental idea of random forests is to combine multiple decision trees into an ensemble model. The procedure of estimating the feature importance using RF is shown as follows: 1. Selecting the out-of-bag (OOB) data for each decision tree and calculating the $O O B$ error denoted by error $_{1} ; 2$. Adding noise to all the samples of factor $X$ randomly and calculating the OOB error again denoted by error $_{2} ; 3$. Calculating the importance of factor $X$ according to the formula below:

$X_{\text {importance }}=\frac{1}{N} \sum_{i=1}^{N}\left(\right.$ error $_{2}-$ error $\left._{1}\right)$,

where $N$ denotes the number of decision trees in an RF model.

\subsection{Sampling}

\subsubsection{First-round sampling}

Based on the definition of landslides by Cruden [15]: 'A landslide is the movement of a mass of rock, earth or debris down a slope.' Landslides occur only in the area with a slope. In other words, landslides would not occur in the areas with the altitude of $0.0 \mathrm{~m}$ and (or) with buildings. According to the real building situation in Penang Island, the majority of buildings are concentrated in a flat area. Therefore, a proper assumption is proposed that the landslides would not occur in the area with elevation of $0.0(\mathrm{~m})$ and (or) landuse of ' 4 ' which denotes buildings. Based on this assumption, a first-round sampling is conducted to clean data and select samples.

The detailed number of each type of pixels removed is shown in Table 3. After the first-round sampling, the total number of the pixels changes from $3,004,631$ $(2,984,386: 20,245)$ to $2,057,379(2,038,606: 18,773)$. The imbalance ratio (IR) of majority to minority samples changes from 147:1 to $108: 1$, which indicates a big decrease on imbalance ratio. The training and validation datasets would be selected from the new dataset with an IR of 108:1.
Table 3 The number of different types of pixels

\begin{tabular}{lccc}
\hline & $\begin{array}{l}\text { No. of non- } \\
\text { landslide } \\
\text { pixels }\end{array}$ & $\begin{array}{l}\text { No. of land- } \\
\text { slide pixels }\end{array}$ & No. of overlapped pixels \\
\hline Elevation & 58,044 & 0 & 32,497 \\
Landuse & 921,705 & 1472 & \\
\hline
\end{tabular}

\subsubsection{Oversampling methods}

Minority samples usually contribute more useful information than majority samples when training ML models in various areas. In landslide spatial area, what we most expect is to predict the landslide accurately. Therefore, increasing the number of landslide samples is of great importance. In order to increase the number of minority samples effectively, three oversampling techniques are considered in this research. Two of them are existing methods, i.e., ROTE and SMOTE. In addition, a new oversampling method, SCOTE, is proposed in this research. After a literature review, the experiments with a balanced sample ratio performed better than those with a high imbalance ratio [52]. Therefore, the sample ratio of the training and validation datasets will be mainly fixed to 1:1 after using different resampling methods in this research. In order to obtain the sample ratio of $1: 1$, random undersampling technique (RUTE) is adopted in combination with the three oversampling methods mentioned above. The samples from the majority class are fixed to be used in model training and validation with three types of minority samples obtained by three different oversampling techniques.

\section{(1) Random oversampling technique (ROTE)}

Random oversampling is a simple sampling technique that aims to balance the distribution of two classes in a dataset through making an exact copy of the minority class samples. The major drawback of ROTE is that it can increase the likelihood of overfitting occurrence to a high degree since it works by supplementing the samples with multiple duplication of the minority class which cannot provide new and useful information to the models. Besides that, ROTE can increase the computing costs, which is also a general drawback of oversampling techniques.

\section{(2) Synthetic Minority Oversampling Technique (SMOTE)}

SMOTE is a widely used and powerful oversampling technique proposed by Chawla et al. [11]. It generates synthetic samples by operating in feature space instead of data space. The neighbors from the $k$ (a parameter) nearest neighbors are randomly chosen based on the number 
of oversampling samples required. Two major steps are required to generate the synthetic samples in SMOTE: 1 . Calculate the difference between the feature vector (sample) and its nearest neighbor; 2 . Multiply this difference by a random number in the range of $[0,1]$, and add it to the concerned feature vector (sample). The mathematical expression of the new samples is shown in Eq. (3):

$\mathbf{x}_{\text {new }}=\mathbf{x}_{i}+\left(\mathbf{x}_{n}-\mathbf{x}_{i}\right) \times \eta$,

where $\mathbf{x}_{i}$ and $\mathbf{x}_{n}$ denote a minority instance and one of its neighbors, respectively. The user-defined parameter $\eta$ is a random number ranging from 0 to 1 . The pseudo-code for SMOTE is available in Chawla et al. [11]. There are three parameters in SMOTE algorithm, namely the number of minority class samples, the amount of SMOTE samples and the number of the nearest neighbors.

One of the advantages of SMOTE is that it can effectively force the decision region of the minority class to become more general. The synthetic samples generated by SMOTE can make the classifier to create larger and less rather than smaller and more specific regions, which can effectively reduce the learning difficulty of the models to a high degree. Another advantage of SMOTE is that it generates new samples based on, but different from, the raw samples which can provide useful information to the models compared to ROTE. From the perspective of the newly generated samples, however, the values of the categorical variables are converted from integer to float, which may make the whole dataset more difficult and complex to learn for the models. In order to solve the problem, a new approach is proposed in the next subsection.

\section{(1) Self-Creating Oversampling Technique (SCOTE)}

SCOTE is proposed in this research, which is an oversampling technique to create new samples. Compared to SMOTE, the categorical variables remain the same instead of being numerical. Only the continuous variables for the minority class (positive) will be used to create new positive samples. The new samples are generated randomly based on the original sample value multiplying a random value $\beta$ which is used to determine the difference between the old and new samples. In this landslide spatial research, the value of $\beta$ is set to the range of $(1.0-0.1,1.0+0.1)$ which denotes an interval on the number line with the center point 1.0 removed. Let $\mathbf{x}_{\text {cat. }}$ and $\mathbf{x}_{\text {con. }}$ be the vectors of categorical and continuous variables, respectively. The mathematical expression of the new samples is shown in Eq. (4):

$\mathbf{x}_{\text {new }}=\left(\mathbf{x}_{\text {cat. }}, x_{\text {con1. }} \times \beta_{1}, x_{\text {con2. }} \times \beta_{2}, \ldots, x_{\text {coni. }} \times \beta_{i}\right)$,

where $\mathbf{x}_{\text {old }}=\left(\mathbf{x}_{\text {cat. }}, \mathbf{x}_{\text {con. }}\right)$. The subscript $i$ denotes the number of continuous variables. An example is illustrated to explain the proposed SCOTE. Consider a sample $(2,3$, $101,32.5)$ where the first two variables, namely the values 2 and 3, are categorical and the last two variables, namely the values 101 and 32.5, are numerical. Suppose the values of $\beta_{1}$ and $\beta_{2}$ are 0.95 and 1.02 , respectively, and based on Eq. (4) the new sample becomes $(2,3,101 * 0.95$, $32.5 * 1.02)=(2,3,95.95,33.15)$. SCOTE is easy to understand and implement through basic statistical software, such as SPSS or Excel.

SCOTE generates'non-exact' examples based on the old samples compared to ROTE. Such inexactness is acceptable for landslide pixel data according to the real situation. For example, Fig. 3 displays a typical landslide occurrence. The gray area denotes the landslide event. The slope angle ( $\alpha$ and $\beta$ ) and elevation $\left(h_{a}\right.$ and $h_{b}$ ) of the landslide area at points $\mathbf{a}$ and $\mathbf{b}$ are obviously different. However, they are both landslide occurrence pixels, which indicates that the values of continuous variables can vary in a small range for a specific landslide event. The main advantage of SCOTE is that it provides new and feasible information to the models for prediction and easiness to obtain new samples compared to ROTE. Furthermore, the data type of the categorical variables remains categorical after SCOTE while being numerical after SMOTE.

\subsubsection{Dataset building}

The three oversampling techniques described in Sect. 3.2.2 are used to double the number of minority samples, from 18,773 to 37,546 . Random undersampling technique (RUTE) is used to select minority and majority samples both in the number of 500 and 5000 for three times, respectively, without replacement. The original data are also considered to build datasets. In order to differentiate the datasets generated using oversampling methods, the datasets generated from the raw data are named as RAW. The datasets with sample size of $1000(10,000)$ are created using 500 (5000) minority and 500 (5000) majority

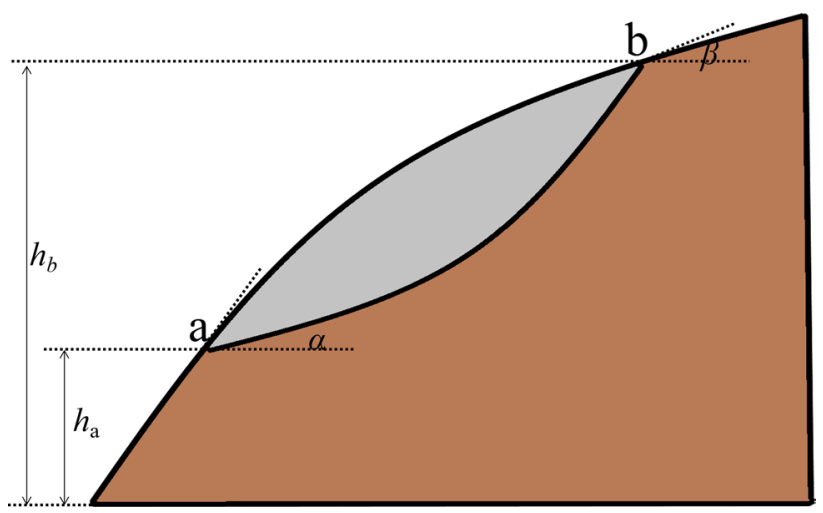

Fig. 3 A typical landslide event 
samples, respectively. The datasets with 5500 samples are made up with 500 minority and 5000 majority samples. Table 4 shows the generation process of each subset.

\subsection{Modeling}

\subsubsection{Support vector machine (SVM)}

SVM classifier was proposed by Cortes and Vapnik [13] based on the statistical learning theory. The two main principles of SVM are the determination of the optimal classification hyperplane and the selection of kernel function [54]. In landslide spatial area, SVM models with RBF have shown satisfactory performance $[9,27,32]$. Therefore, in this research, SVM models with RBF kernel are applied to conduct landslide spatial research and produce LSMs. The mathematical expression of RBF is shown in Eq. (5):

$K\left(\mathbf{x}_{i}, \mathbf{x}_{j}\right)=e^{-\gamma\left(\mathbf{x}_{i}-\mathbf{x}_{j}\right)^{2}}, \gamma>0$,

where the parameter gamma $(\gamma)$ is a user-defined parameter to determine the number of support vectors. The larger the gamma value, the less the number of support vectors. The optimal classification hyperplane of SVM is displayed in Eq. (6):

minimize: $\frac{1}{2}\|\mathbf{w}\|^{2}+C \sum_{i=1}^{n} \xi_{i}$

subject to: $y_{i}\left(\mathbf{w}^{\top} \phi(\mathbf{x})+b\right) \geq 1-\xi_{i}, \xi_{i} \geq 0, i=1,2, \ldots, n$,

where $\mathbf{w}=\left(w_{1}, w_{2}, \ldots, w_{n}\right)$ denotes the normal vector which determines the direction of the hyperplane and $b$ is the displacement which determines the distance from the origin to the hyperplane. The term $\left(\mathbf{w}^{\top} \phi(\mathbf{x})+b\right)$ can be regarded as the landslide susceptibility index (LSI), according to which the LSMs are produced. The parameters $\xi_{i}$ denote the slack variables. Based on trial and error, the intervals of the parameter $C$ and gamma are set to [0.1, $300]$ and $[0.1,10]$, respectively.

\subsubsection{Logistic regression (LR)}

LR was proposed by Cox [14], which is a widely used statistical binary classifier. The goal of $L R$ is to find the best fitting model to describe the relationship between the dependent variable and a set of independent variables. The simplest form of logistic function is shown in Eq. (7) $[44,48]$ as:

$\sigma(y)=\frac{1}{\left(1+e^{-y}\right)}$

which is also called sigmoid function because it is an $S$-shaped curve. The value of $\sigma(y)$ ranges from 0 to 1 no matter what value of $y$ takes where $y$ is usually considered as a linear regression function. The advantage of $L R$ is it does not assume that the independent variables are normally distributed.

\subsection{Performance measures}

\subsubsection{Scalar metrics}

The performance measures for model validation play an essential role in measuring the generalization ability of ML models. Different performance measure metrics may lead to different results. For binary classification problems, the testing samples can be classified into four categories based on the predicted label and the true label: true positive (TP), false positive (FP), true negative (TN), false negative (FN). The confusion matrix of the prediction results is displayed in Table 5.

Table 5 The confusion matrix

\begin{tabular}{lll}
\hline Confusion matrix & Predicted label & \\
\cline { 2 - 3 } & Positive & Negative \\
\hline True label & & \\
Positive & TP & FN \\
Negative & FP & TN \\
\hline
\end{tabular}

Table 4 Datasets building

\begin{tabular}{|c|c|c|c|c|c|c|c|c|c|c|}
\hline \multirow[t]{3}{*}{ Sampling } & \multicolumn{5}{|c|}{1000 samples } & \multicolumn{5}{|c|}{10,000 samples } \\
\hline & \multicolumn{4}{|c|}{ Minority } & \multirow{2}{*}{$\begin{array}{l}\text { Majority } \\
\text { ROTE }\end{array}$} & \multicolumn{4}{|c|}{ Minority } & \multirow{2}{*}{$\begin{array}{l}\text { Majority } \\
\text { ROTE }\end{array}$} \\
\hline & RAW & ROTE & SMOTE & SCOTE & & RAW & ROTE & SMOTE & SCOTE & \\
\hline \multirow[t]{3}{*}{ No. of samples } & $500^{1}$ & $500^{1}$ & $500^{1}$ & $500^{1}$ & \multirow[t]{3}{*}{500} & $5000^{1}$ & $5000^{1}$ & $5000^{1}$ & $5000^{1}$ & \multirow[t]{3}{*}{5000} \\
\hline & $500^{2}$ & $500^{2}$ & $500^{2}$ & $500^{2}$ & & $5000^{2}$ & $5000^{2}$ & $5000^{2}$ & $5000^{2}$ & \\
\hline & $500^{3}$ & $500^{3}$ & $500^{3}$ & $500^{3}$ & & $5000^{3}$ & $5000^{3}$ & $5000^{3}$ & $5000^{3}$ & \\
\hline
\end{tabular}

The superscripts indicate the serial number of the datasets 
Accuracy, recall and precision are commonly used to measure the performance of binary classifiers. The definitions of accuracy, recall and precision are shown in Eqs. (8)-(10), respectively. $F_{\beta}$ score is the weighted harmonic mean of the recall and precision. $F_{1}$ score is a special case of $F_{\beta}$ when $\beta=1$. The parameter $\beta$ measures the relative importance between recall and precision. The mathematical expression of $F_{1}$ score is shown in Eq. (11).

Accuracy $=\frac{\mathrm{TP}+\mathrm{TF}}{\mathrm{TP}+\mathrm{FP}+\mathrm{TF}+\mathrm{FN}}$

Recall $=\frac{T P}{T P+F N}$

Precision $=\frac{\mathrm{TP}}{\mathrm{TP}+\mathrm{FP}}$

$F_{1}$ Score $=\frac{2 \cdot \text { recall } \cdot \text { precision }}{\text { precision }+ \text { recall }}$

\subsubsection{Receiver operator characteristic (ROC)}

For the scalar performance metrics, it is difficult to provide comprehensive information for performance measures. In ML area, the models usually produce a continuous value as the prediction result. Therefore, a threshold value is needed when transforming the continuous value to a binary label value. However, a threshold value is needed when transforming the continuous value to a binary label value. The selection to the threshold value highly affects the results of performance measures. Receiver operator characteristic (ROC) curve is a commonly used metric to validate models compared to the scalar metrics. The threshold selection problem can be avoided by replacing the accuracy with area under the ROC curve (AUC) as the main metric for model validation. ROC curves depict the tradeoff between the true positive rate (recall) and false positive rate (1-precision). They measure the ability of a classifier to rank the positive samples relative to the negative samples. The AUC values can be regarded as the probability that a classifier ranks a randomly chosen positive sample higher than a randomly chosen negative sample [19].

\subsubsection{Cost curve}

Cost curve is another popular method to measure the performance of models, which is proposed by Drummond and Holte [17]. Before discussing cost curve in detail, cost matrices are introduced to describe the costs from different classifications. The rows and columns of a cost matrix correspond to the predicted and actual classes, respectively. The $\operatorname{cost} c_{i j}(i, j=0$ or 1$)$ denotes the cost of classifying an example of class $j$ as class $i$. For example, $c_{01}$ means the cost of misclassifying a positive sample to a negative sample. The cost of classifying a sample incorrectly should always be greater than the cost of correctly classifying a sample; namely, $c_{01}$ and $c_{10}$ are always greater than $c_{00}$ and $c_{11}$. Usually, $c_{i j}=0$ when $i=j$. The cost matrix with equal and unequal misclassification costs is displayed in Table 6 .

Cost curve is a graphical technique for visualizing the performance of two-class classifiers over the full range of the possible class distribution and misclassification cost [17]. Figure 4 displays a typical cost curve. The cost curve represents the normalized expected cost of a probability cost function [20]. The goal of cost curve is to minimize the expected total cost (ETC) rather than the number of misclassifications [56]. The standard performance measures, such as AUC, usually assume the equal classification costs. In the case of unequal costs, ROC curves fail to represent the ETC directly. The definition of expected cost (EC) can be expressed as:

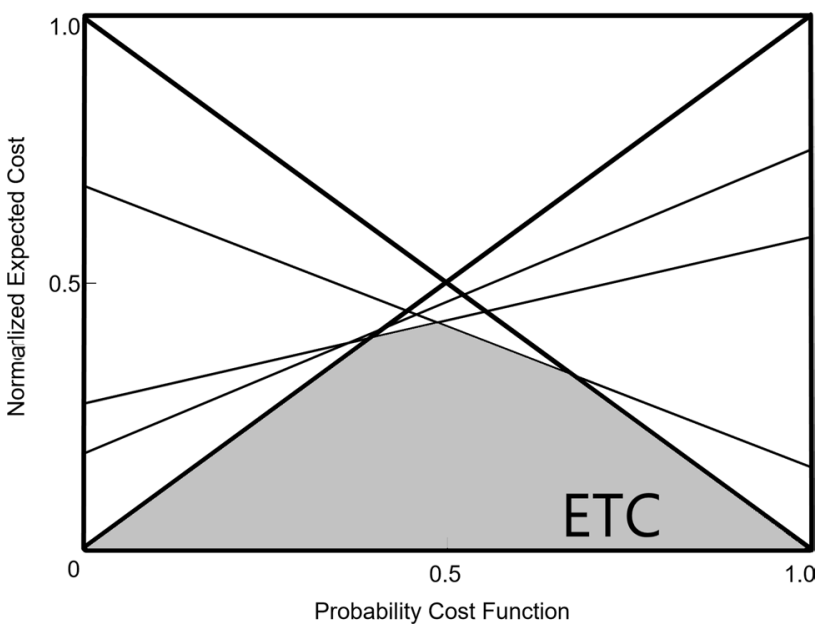

Fig. 4 A typical cost curve
Table 6 Cost matrix of costinsensitive and cost-sensitive performance metrics

\begin{tabular}{llllll}
\hline & \multicolumn{2}{l}{ Equal cost } & & \multicolumn{2}{l}{ Unequal cost } \\
\cline { 2 - 3 } \cline { 5 - 6 } & Actual negative & Actual positive & & Actual negative & Actual positive \\
\hline Predicted negative & $c_{00}=0$ & $c_{01}=1$ & $c_{00}=0$ & $c_{01}=\mathrm{a}(>1)$ \\
Predicted positive & $c_{10}=1$ & $c_{11}=0$ & & $c_{10}=1$ & $c_{11}=0$ \\
\hline
\end{tabular}


$\mathrm{EC}=\mathrm{FNR} \times p \times c_{01}+\mathrm{FPR} \times(1-p) \times c_{10}$.

where FPR and FNR are defined in Eqs. (13) and (14):

$\mathrm{FPR}=\frac{\mathrm{FP}}{\mathrm{FP}+\mathrm{TN}}$.

$F N R=\frac{F N}{F N+T P}$.

and the meanings of FP, TN, FN and TP are provided in Session 3.4.1. The probability $p$ in Eq. (12) denotes the a priori probability of positive samples. The a priori probability $p$ is assumed to be a condition of equal-probability [20]. The ETC can be expressed as the area of the gray polygon in Fig. 4. The smaller the ETC value, the better the model performs. In this research, the cost of misclassifying a landslide pixel to non-landslide pixel is set to 100 based on expert experience, whereas the misclassification of a nonlandslide pixel to a landslide pixel is 1 .

\section{Results}

All the experiments are conducted mainly based on the sklearn, numpy, scipy, pandas libraries in Python 3.7 in a Windows 10 server with an Intel Core i5 $2.40 \mathrm{GHz}$ processor. SPSS 20.0 is used for datasets preparation and nonparametric tests. The results of the multicollinearity analysis and RF are shown in Table 7. According to the results of multicollinearity analysis, all the features in all datasets show no multicollinearity based on VIF values $(<5)$. Therefore, no influencing factors are removed from the datasets. For the results of RF, the feature importance values of the factor 'Soil' are all lower than 0.01 , which shows the least importance among all features. The factor 'elevation' shows the highest feature importance in most of the datasets generated using by ROTE, SMOTE and SCOTE with bold fonts in Table 7. The factor 'distance to fault' appears to be the highest in certain datasets.

The results of scalar metrics of accuracy, recall, precision and $F_{1}$ score are shown in Table 8. Even though they are considered as the less important metrics for model validation in this research, they provide some useful information as well, especially the recall metric, which describes the relationship between true positives and the total number of true positives and false negatives. The highest values of recall are 0.808 and 0.705 for SVM and LR, respectively. The corresponding datasets with 10,000 samples are both generated by SCOTE.

The results of ROCs and CCs are shown in Table 9. Figure 5 displays the AUC curves of all the SVM and LR models. The highest AUC values are 0.8927 and 0.7828 for SVM and LR, respectively. The smallest ETC values are 0.0974 and 0.1430 for SVM and LR classifiers, respectively. The CC for the two models trained using the datasets with 10,000 samples generated using SCOTE is shown in Fig. 6. All the optimal values occur in the models trained by the datasets with 10,000 samples in the SCOTE group, namely SCOTE_10000_1. According to the highest AUC and ETC values, two SVM models, trained using the dataset SCOTE_10000_1 and SCOTE_10000_2, are applied to produce the LSMs. The results displayed in Table 9 indicate that the newly proposed oversampling method SCOTE somewhat outperforms ROTE and SMOTE as well as the original data to some degree. Based on the AUC and ETC values, the SVM models trained using the datasets with 10,000 samples show the best performance. The SVM models are more sensitive to the sample size than LR models. For example, the average AUC values of SVM models trained using $1000,10,000$ and 5500 samples are 0.7629 , 0.8875 and 0.7993 , respectively. The counterpart average values for LR models are $0.7676,0.7812$ and 0.7790 , respectively. Kruskal-Wallis test [16] is used to determine whether there are statistically significant differences between groups, respectively, based on the AUC and ETC values obtained by the process of performance measures. Table 10 gives a description on the results of Kruskal-Wallis test with $p$ values of 0.000 . It indicates that the larger the sample size, the better the performance. The difference between the results obtained by different sampling methods is quite small, but it can be at least said that the proposed oversampling method has the same efficiency with other methods. Furthermore, SCOTE is much easier to implement than other oversampling methods.

After evaluating the models based on AUC values of ROC and ETC values of CC curves, the verification analysis is conducted by comparing the prediction results with the existing landslide data based on two key assumptions [44]. The first one is that the landslide occurrences are related to the spatial distribution. Another one is that landslides are controlled by some influencing factors, which can be analyzed statistically or empirically. The LSI values for the two SVM trained using the dataset SCOTE_10000_1 (SVM_1) and SCOTE_10000_2 (SVM_2) are sorted in a descending order and then classified into four susceptibility categories: 'Very High [0-10\%],' 'High [10-20\%],' 'Medium [20-60\%]' and 'Low [60-100\%].'The verification results for the two SVM models are displayed in Fig. 7. The susceptible area denotes the sum of the percentages of 'Very High' and 'High' category, namely the first $20 \%$ of the LSI values of each dataset after being sorted in a descending order. Based on the percentage value of 'Very High' and 'High' categories, the first 20 percent of the LSI values successfully predict $86.4 \%$ and $86.2 \%$ of the susceptible area for SVM_1 and SVM_2 models, respectively. Furthermore, the LSMs 


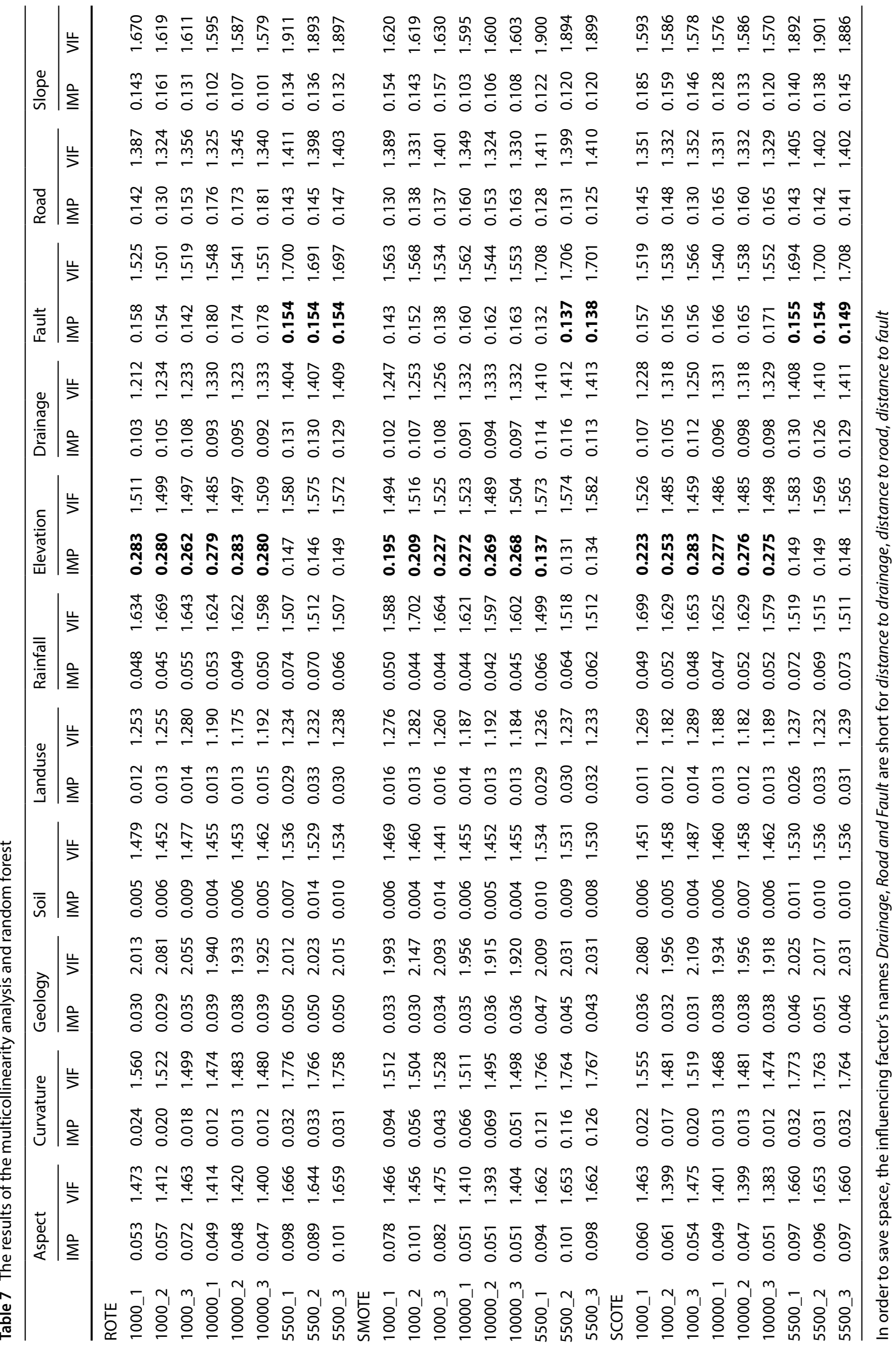


Table 8 The results of SVMs trained using three oversampling techniques

\begin{tabular}{|c|c|c|c|c|c|c|c|c|}
\hline \multirow[t]{2}{*}{ Classifier } & \multirow[t]{2}{*}{ Sampling } & \multirow[t]{2}{*}{ Dataset } & \multicolumn{3}{|c|}{ Accuracy (\%) } & \multirow[t]{2}{*}{ Recall } & \multirow[t]{2}{*}{ Precision } & \multirow[t]{2}{*}{ F1_score } \\
\hline & & & Training & Validation & Overall & & & \\
\hline \multirow[t]{48}{*}{ SVM } & \multirow[t]{4}{*}{ RAW } & 1000_1 & 99.4 & 97.5 & 76.0 & 0.678 & 0.018 & 0.037 \\
\hline & & 1000_2 & 99.9 & 99.9 & 78.1 & 0.594 & 0.018 & 0.035 \\
\hline & & 1000_3 & 98.3 & 98.5 & 80.0 & 0.585 & 0.020 & 0.038 \\
\hline & & Average & 99.4 & 97.5 & 76.0 & 0.678 & 0.018 & 0.037 \\
\hline & \multirow[t]{4}{*}{ ROTE } & 1000_1 & 99.0 & 99.5 & 75.1 & 0.669 & 0.018 & 0.035 \\
\hline & & 1000_2 & 92.0 & 89.0 & 73.2 & 0.645 & 0.016 & 0.031 \\
\hline & & 1000_3 & 99.6 & 100 & 76.4 & 0.611 & 0.017 & 0.034 \\
\hline & & Average & 96.9 & 96.2 & 74.9 & 0.642 & 0.017 & 0.033 \\
\hline & \multirow[t]{4}{*}{ SMOTE } & 1000_1 & 95.3 & 93.5 & 80.2 & 0.598 & 0.020 & 0.039 \\
\hline & & 1000_2 & 99.5 & 99.0 & 78.3 & 0.628 & 0.019 & 0.037 \\
\hline & & 1000_3 & 93.4 & 97.0 & 77.1 & 0.664 & 0.019 & 0.038 \\
\hline & & Average & 96.1 & 96.5 & 78.5 & 0.630 & 0.019 & 0.038 \\
\hline & \multirow[t]{4}{*}{ SCOTE } & 1000_1 & 99.8 & 99.5 & 77.3 & 0.635 & 0.019 & 0.036 \\
\hline & & 1000_2 & 99.6 & 99.5 & 78.4 & 0.607 & 0.019 & 0.036 \\
\hline & & 1000_3 & 92.8 & 91.5 & 76.6 & 0.672 & 0.019 & 0.037 \\
\hline & & Average & 97.4 & 96.8 & 77.4 & 0.638 & 0.019 & 0.036 \\
\hline & \multirow[t]{4}{*}{ RAW } & 10000_1 & 97.3 & 96.6 & 85.8 & 0.792 & 0.037 & 0.070 \\
\hline & & 10000_2 & 97.8 & 97.9 & 86.4 & 0.783 & 0.038 & 0.072 \\
\hline & & 10000_3 & 97.1 & 97.4 & 86.1 & 0.782 & 0.037 & 0.071 \\
\hline & & Average & 97.3 & 96.6 & 85.8 & 0.792 & 0.037 & 0.070 \\
\hline & \multirow[t]{4}{*}{ ROTE } & 10000_1 & 97.0 & 97.5 & 85.9 & 0.800 & 0.037 & 0.071 \\
\hline & & 10000_2 & 97.7 & 97.7 & 86.5 & 0.774 & 0.038 & 0.072 \\
\hline & & 10000_3 & 97.7 & 97.3 & 86.3 & 0.765 & 0.037 & 0.070 \\
\hline & & Average & 97.0 & 97.5 & 85.9 & 0.800 & 0.037 & 0.071 \\
\hline & \multirow[t]{4}{*}{ SMOTE } & 10000_1 & 98.1 & 98.2 & 87.5 & 0.709 & 0.037 & 0.071 \\
\hline & & 10000_2 & 96.9 & 96.8 & 86.1 & 0.763 & 0.036 & 0.069 \\
\hline & & 10000_3 & 95.9 & 96.2 & 86.8 & 0.767 & 0.038 & 0.073 \\
\hline & & Average & 98.1 & 98.2 & 87.5 & 0.709 & 0.037 & 0.071 \\
\hline & \multirow[t]{4}{*}{ SCOTE } & 10000_1 & 96.1 & 95.2 & 85.9 & 0.801 & 0.037 & 0.071 \\
\hline & & 10000_2 & 97.1 & 96.8 & 85.7 & 0.808 & 0.037 & 0.071 \\
\hline & & 10000_3 & 98.2 & 98.3 & 85.6 & 0.781 & 0.036 & 0.068 \\
\hline & & Average & 96.1 & 95.2 & 85.9 & 0.801 & 0.037 & 0.071 \\
\hline & \multirow[t]{4}{*}{ RAW } & 5500_1 & 91.8 & 90.4 & 99.2 & 0.024 & 0.097 & 0.039 \\
\hline & & 5500_2 & 91.2 & 91.5 & 99.3 & 0.013 & 0.146 & 0.024 \\
\hline & & 5500_3 & 90.8 & 91.5 & 99.3 & 0.001 & 0.271 & 0.002 \\
\hline & & Average & 91.3 & 91.1 & 99.3 & 0.013 & 0.171 & 0.022 \\
\hline & \multirow[t]{4}{*}{ ROTE } & 5500_1 & 91.0 & 90.8 & 99.3 & 0.000 & 0.571 & 0.001 \\
\hline & & 5500_2 & 91.8 & 90.5 & 99.0 & 0.021 & 0.038 & 0.027 \\
\hline & & 5500_3 & 91.0 & 91.5 & 99.3 & 0.006 & 0.140 & 0.011 \\
\hline & & Average & 91.3 & 90.9 & 99.2 & 0.009 & 0.250 & 0.013 \\
\hline & \multirow[t]{4}{*}{ SMOTE } & 5500_1 & 93.0 & 93.1 & 99.2 & 0.030 & 0.109 & 0.047 \\
\hline & & 5500_2 & 92.0 & 92.1 & 99.3 & 0.012 & 0.253 & 0.023 \\
\hline & & 5500_3 & 92.7 & 90.8 & 99.2 & 0.020 & 0.087 & 0.032 \\
\hline & & Average & 92.6 & 92.0 & 99.2 & 0.021 & 0.150 & 0.034 \\
\hline & \multirow[t]{4}{*}{ SCOTE } & 5500_1 & 91.9 & 91.7 & 99.2 & 0.022 & 0.121 & 0.037 \\
\hline & & 5500_2 & 91.4 & 90.5 & 99.3 & 0.007 & 0.229 & 0.014 \\
\hline & & 5500_3 & 91.4 & 92.1 & 99.0 & 0.031 & 0.065 & 0.042 \\
\hline & & Average & 91.6 & 91.4 & 99.2 & 0.020 & 0.138 & 0.031 \\
\hline
\end{tabular}


Table 8 (continued)

\begin{tabular}{|c|c|c|c|c|c|c|c|c|}
\hline \multirow[t]{2}{*}{ Classifier } & \multirow[t]{2}{*}{ Sampling } & \multirow[t]{2}{*}{ Dataset } & \multicolumn{3}{|c|}{ Accuracy (\%) } & \multirow[t]{2}{*}{ Recall } & \multirow[t]{2}{*}{ Precision } & \multirow[t]{2}{*}{ F1_score } \\
\hline & & & Training & Validation & Overall & & & \\
\hline \multirow[t]{48}{*}{ LR } & \multirow{4}{*}{ RAW } & 1000_1 & 65.2 & 64.0 & 72.2 & 0.637 & 0.015 & 0.030 \\
\hline & & 1000_2 & 65.1 & 62.0 & 77.2 & 0.551 & 0.016 & 0.032 \\
\hline & & 1000_3 & 64.9 & 62.0 & 76.1 & 0.553 & 0.016 & 0.030 \\
\hline & & Average & 65.1 & 62.7 & 75.2 & 0.580 & 0.016 & 0.031 \\
\hline & \multirow{4}{*}{ ROTE } & 1000_1 & 64.6 & 60.0 & 73.2 & 0.613 & 0.015 & 0.030 \\
\hline & & 1000_2 & 66.1 & 59.0 & 75.3 & 0.606 & 0.016 & 0.032 \\
\hline & & 1000_3 & 65.4 & 65.0 & 73.1 & 0.606 & 0.015 & 0.029 \\
\hline & & Average & 65.4 & 61.3 & 73.9 & 0.608 & 0.015 & 0.030 \\
\hline & \multirow{4}{*}{ SMOTE } & 1000_1 & 67.8 & 65.0 & 76.0 & 0.562 & 0.016 & 0.031 \\
\hline & & 1000_2 & 63.4 & 74.0 & 75.4 & 0.585 & 0.016 & 0.031 \\
\hline & & 1000_3 & 66.6 & 54.0 & 68.5 & 0.705 & 0.015 & 0.029 \\
\hline & & Average & 65.9 & 64.3 & 73.3 & 0.617 & 0.016 & 0.030 \\
\hline & \multirow{4}{*}{ SCOTE } & 1000_1 & 65.6 & 68.0 & 73.4 & 0.623 & 0.016 & 0.031 \\
\hline & & 1000_2 & 67.4 & 56.0 & 75.2 & 0.590 & 0.016 & 0.031 \\
\hline & & 1000_3 & 67.3 & 62.0 & 76.0 & 0.570 & 0.016 & 0.031 \\
\hline & & Average & 66.8 & 62.0 & 74.9 & 0.594 & 0.016 & 0.031 \\
\hline & \multirow[t]{4}{*}{ RAW } & 10000_1 & 64.9 & 62.9 & 74.2 & 0.628 & 0.016 & 0.032 \\
\hline & & 10000_2 & 64.8 & 64.3 & 74.6 & 0.622 & 0.016 & 0.031 \\
\hline & & 10000_3 & 64.9 & 65.8 & 74.6 & 0.622 & 0.016 & 0.032 \\
\hline & & Average & 64.9 & 64.3 & 74.5 & 0.624 & 0.016 & 0.032 \\
\hline & \multirow{4}{*}{ ROTE } & 10000_1 & 64.6 & 65.7 & 73.9 & 0.636 & 0.016 & 0.032 \\
\hline & & 10000_2 & 64.8 & 62.5 & 74.1 & 0.629 & 0.016 & 0.032 \\
\hline & & 10000_3 & 65.1 & 66.9 & 74.3 & 0.628 & 0.016 & 0.032 \\
\hline & & Average & 64.8 & 65.0 & 74.1 & 0.631 & 0.016 & 0.032 \\
\hline & \multirow{4}{*}{ SMOTE } & 10000_1 & 64.8 & 64.7 & 75.6 & 0.608 & 0.017 & 0.033 \\
\hline & & 10000_2 & 64.7 & 65.3 & 73.3 & 0.643 & 0.016 & 0.031 \\
\hline & & 10000_3 & 64.8 & 66.8 & 75.1 & 0.618 & 0.016 & 0.032 \\
\hline & & Average & 64.8 & 65.6 & 74.7 & 0.623 & 0.016 & 0.032 \\
\hline & \multirow{4}{*}{ SCOTE } & 10000_1 & 64.9 & 66.8 & 73.0 & 0.649 & 0.016 & 0.031 \\
\hline & & 10000_2 & 64.9 & 64.5 & 73.0 & 0.659 & 0.016 & 0.032 \\
\hline & & 10000_3 & 64.6 & 63.7 & 73.1 & 0.648 & 0.016 & 0.031 \\
\hline & & Average & 64.8 & 65.0 & 73.0 & 0.652 & 0.016 & 0.031 \\
\hline & \multirow{4}{*}{ RAW } & 5500_1 & 90.8 & 92.0 & 99.3 & 0.000 & - & - \\
\hline & & 5500_2 & 90.9 & 90.5 & 99.3 & 0.000 & - & - \\
\hline & & 5500_3 & 90.9 & 91.1 & 99.3 & 0.000 & - & - \\
\hline & & Average & 90.9 & 91.2 & 99.3 & 0.000 & - & - \\
\hline & \multirow{4}{*}{ ROTE } & 5500_1 & 90.7 & 92.3 & 99.3 & 0.000 & - & - \\
\hline & & 5500_2 & 90.8 & 91.6 & 99.3 & 0.000 & - & - \\
\hline & & 5500_3 & 90.8 & 92.0 & 99.3 & 0.000 & - & - \\
\hline & & Average & 90.8 & 92.0 & 99.3 & 0.000 & - & - \\
\hline & \multirow{4}{*}{ SMOTE } & 5500_1 & 90.9 & 90.7 & 99.3 & 0.000 & - & - \\
\hline & & 5500_2 & 91.0 & 89.8 & 99.3 & 0.000 & - & - \\
\hline & & 5500_3 & 90.8 & 91.8 & 99.3 & 0.000 & - & - \\
\hline & & Average & 90.9 & 90.8 & 99.3 & 0.000 & - & - \\
\hline & \multirow{4}{*}{ SCOTE } & 5500_1 & 90.9 & 90.9 & 99.3 & 0.000 & - & - \\
\hline & & 5500_2 & 90.8 & 91.5 & 99.3 & 0.000 & - & - \\
\hline & & 5500_3 & 90.8 & 91.8 & 99.3 & 0.000 & - & - \\
\hline & & Average & 90.8 & 91.4 & 99.3 & 0.000 & - & - \\
\hline
\end{tabular}


are produced using the two models trained and validated using the SCOTE_10000_1 dataset. Figure 8 displays the LSMs. The susceptible area is mainly located in the middle mountainous region and the northwestern area, which is highly consistent with the landslide history displayed in Fig. 1. The maps can provide useful information on landslide mitigation and prediction to relevant authorities to a high degree.

\section{Discussions}

In this research, three oversampling methods, namely ROTE, SMOTE and SCOTE, are used to augment the landslide samples. The datasets composed of newly produced landslide and non-landslide samples are then used to train the models: LR and SVM. Multicollinearity analysis and RF are used to preprocess the data. ROC curves are considered as the main metric to measure the models' performances or the efficiency of the oversampling methods. The results show that the dataset with the landslide pixel data produced by SCOTE trains a slightly better model than the data produced by other oversampling method under the condition of the same non-landslide pixels. It indicates that the newly proposed SCOTE is at least effective to produce new samples.

There are 382 landslide occurrences available in this research, which are split into 20,245 landslide pixels where the total number of pixels for Penang Island is $3,004,631$. Three oversampling methods are applied to augment the landslide pixel data after random undersampling. These oversampling methods seem better to be applied to the data with 382 landslide occurrences, since the number of 20,245 landslide pixels is not that small. However, pixel data are more accurate to describe the characteristic of a landslide, especially for the large landslides. For example, the largest landslide in this research covers around $39,800 \mathrm{~m}^{2}$, it is very difficult to use only one landslide sample to describe in a comprehensive way. On the contrary, the area of a pixel is $10 \mathrm{~m}^{2}$, which can provide a more accurate description. Therefore, the landslide pixel data $(20,245)$ are used as the raw data to augment new landslide samples instead of the landslide occurrences data (382).

There are several limitations that need to be taken into consideration. First of all, in this study, we adopt several oversampling methods to produce landslide samples which are considered to have similar prediction power as the original landslide samples according to the results. However, it may overestimate the hazard of large landslides and underestimate the hazard of small landslides. The additional computations are better performed in future researches. Secondly, the landslide inventory used in this research was recorded around one decade ago, which is not the latest landslide inventory. Therefore, the assumption proposed in Sect. 3.2.1 is difficult to verify the accuracy. Moreover, cost curves are used in this research to evaluate the models' performances. The cost of misclassifying a landslide sample wrongly is set to 100 which is very close to the sample imbalance ratio (108:1) mentioned in Sect. 3.2.1. However, it is unrelated to the sample ratio. The determination of the misclassifying cost is quite subjective to a high degree. Other values can be adopted in the future research. Last but not least, the landslides that occurred after finishing the landslide inventory (including 382 landslide occurrences) are being unavailable for consideration when conducting the research, which may have wrongly considered some landslide pixels to be non-landslide pixels. Future research can focus on the direction of the verification.

\section{Conclusions}

A total of 382 previous landslide occurrences as well as eleven landslide conditioning factors are considered to produce LSMs using SVM and LR models. During the model training process, several oversampling techniques are applied to create minority samples with efficiency, such as RUTE, SMOTE and the newly proposed SCOTE. In general, the results show that the models, both for SVM_1 and SVM_2, trained using the datasets generated by SCOTE have better prediction performance based on the AUC and ETC values, which suggests that SCOTE is an efficient method to augment samples. The values for SVM_1 model are 0.8927 and 0.0974 for ROC and CC curves, respectively. For SVM_2 model, the corresponding values are 0.8920 and 0.0977 , respectively. The comparison results between SVM and LR models indicate that the oversampling method is efficient to augment the landslide data to some degree, especially when the sample size is small. Although the differences among the results obtained by different 
Table 9 The AUC and ETC values for SVM and LR models

\begin{tabular}{|c|c|c|c|c|c|c|c|c|c|}
\hline & \multicolumn{3}{|l|}{1000} & \multicolumn{3}{|l|}{10000} & \multicolumn{3}{|l|}{5500} \\
\hline & 1 & 2 & 3 & 1 & 2 & 3 & 1 & 2 & 3 \\
\hline \multicolumn{10}{|l|}{ SVM } \\
\hline \multicolumn{10}{|l|}{ RAW } \\
\hline AUC & 0.7726 & 0.7382 & 0.7551 & 0.8915 & 0.8898 & 0.8904 & 0.7979 & 0.8031 & 0.7881 \\
\hline ETC & 0.1623 & 0.1747 & 0.1698 & 0.1072 & 0.1071 & 0.1079 & 0.1631 & 0.1607 & 0.1667 \\
\hline \multicolumn{10}{|l|}{ ROTE } \\
\hline AUC & 0.7596 & 0.7723 & 0.7381 & 0.8871 & 0.8881 & 0.8847 & 0.7812 & 0.8046 & 0.8115 \\
\hline ETC & 0.1664 & 0.1709 & 0.1757 & 0.1064 & 0.1084 & 0.1114 & 0.1664 & 0.1611 & 0.1566 \\
\hline \multicolumn{10}{|l|}{ SMOTE } \\
\hline AUC & 0.7773 & 0.7665 & 0.7837 & 0.8739 & 0.8834 & 0.8920 & 0.7923 & 0.7979 & 0.7908 \\
\hline ETC & 0.1621 & 0.1648 & 0.1617 & 0.1171 & 0.1120 & 0.1069 & 0.1617 & 0.1615 & 0.1668 \\
\hline \multicolumn{10}{|l|}{ SCOTE } \\
\hline AUC & 0.7468 & 0.75627 & 0.7884 & 0.8927 & 0.8918 & 0.8850 & 0.8039 & 0.8046 & 0.8161 \\
\hline ETC & 0.1698 & 0.1702 & 0.1600 & 0.1046 & 0.1046 & 0.1102 & 0.1533 & 0.1604 & 0.1565 \\
\hline Avg. AUC/ETC & $0.7629 / 0.1668$ & & & $0.8875 / 0.1003$ & & & $0.7993 / 0.1494$ & & \\
\hline \multicolumn{10}{|l|}{ LR } \\
\hline \multicolumn{10}{|l|}{ RAW } \\
\hline AUC & 0.7681 & 0.7653 & 0.7594 & 0.7817 & 0.7797 & 0.7809 & 0.7789 & 0.7787 & 0.7771 \\
\hline ETC & 0.1749 & 0.1768 & 0.1784 & 0.1702 & 0.1709 & 0.1701 & 0.1714 & 0.1716 & 0.1722 \\
\hline \multicolumn{10}{|l|}{ ROTE } \\
\hline AUC & 0.7689 & 0.7779 & 0.7628 & 0.7812 & 0.7820 & 0.7817 & 0.7812 & 0.7798 & 0.7767 \\
\hline ETC & 0.1727 & 0.1716 & 0.1767 & 0.1699 & 0.1693 & 0.1697 & 0.1695 & 0.1723 & 0.1719 \\
\hline \multicolumn{10}{|l|}{ SMOTE } \\
\hline AUC & 0.7641 & 0.7722 & 0.7706 & 0.7822 & 0.7797 & 0.7809 & 0.7777 & 0.7795 & 0.7801 \\
\hline ETC & 0.1759 & 0.1730 & 0.1740 & 0.1704 & 0.1706 & 0.1704 & 0.1708 & 0.1722 & 0.1719 \\
\hline \multicolumn{10}{|l|}{ SCOTE } \\
\hline AUC & 0.7654 & 0.7700 & 0.7664 & 0.7804 & 0.7828 & 0.7809 & 0.7788 & 0.7799 & 0.7796 \\
\hline ETC & 0.1768 & 0.1745 & 0.1753 & 0.1699 & 0.1700 & 0.1702 & 0.1704 & 0.1728 & 0.1714 \\
\hline Avg. AUC/ETC & $0.7676 / 0.1751$ & & & $0.7812 / 0.1701$ & & & $0.7790 / 0.1715$ & & \\
\hline
\end{tabular}

oversampling methods are quite small when the sample size is getting larger, the proposed SCOTE is easy to understand and operate compared to SMOTE. The results of nonparametric test show that LR models are less sensitive to sample size compared to SVM models. More classification models can be employed in future research.

Furthermore, random forests technique is applied to measure the importance of the eleven landslide influencing factors. The factor 'Height' is of great importance in the available landslide dataset followed by the factor 'distance to fault.' In this research, the factor 'Soil' shows the smallest $O O B$ score. Usually, the features with least importance can be removed from the models. However, soil type is important to landslide spatial prediction based on the previous literature and experts' experience. Therefore, no factors are removed from the models when producing LSMs in the research.

Compared to previous researches, this paper puts more emphasis on the oversampling methods, which is of greater importance to those research data with less minority samples. Two popular machine learning models are applied to produce LSMs based on the three oversampling methods. In summary, the LSMs produced by SVM models based on SCOTE can provide useful and accurate information to the local authority when making decisions on landslide management and mitigation. 
Fig. 5 ROC curves for a SVM trained with 1000 samples; b LR trained with 1000 samples; c SVM trained with 10,000 samples; d LR trained with 10,000 samples; e SVM trained with 5500 samples; $f$ LR trained with 5500 samples

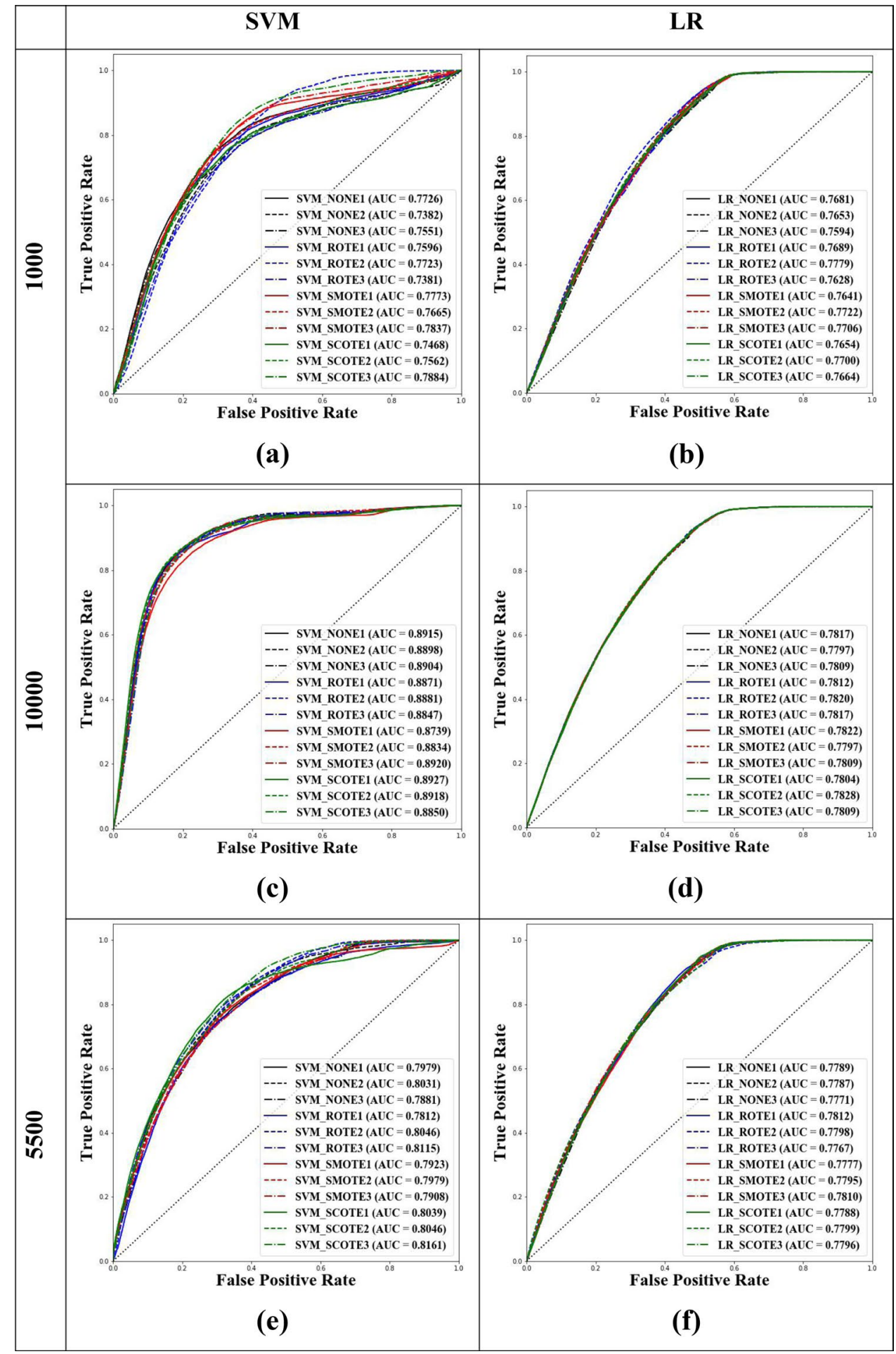




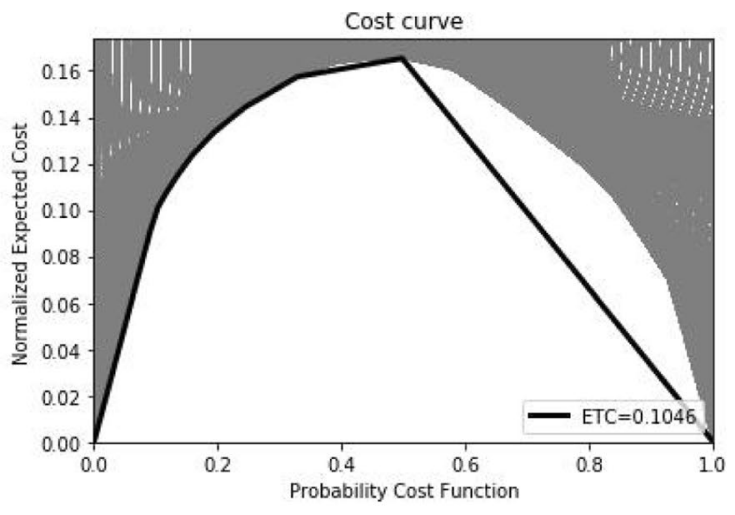

(a)

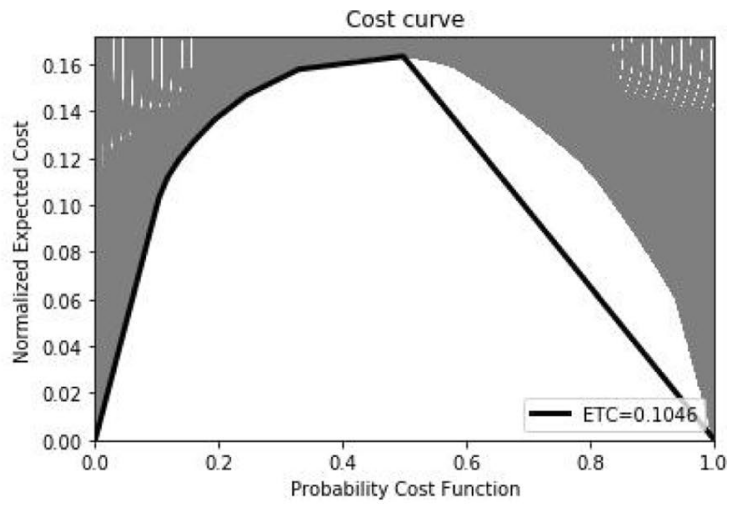

(b)

Fig. 6 Cost curves for: a SVM trained with dataset SCOTE_10000_1; b SVM trained with dataset SCOTE_10000_2

Table 10 Kruskal-Wallis test on different sample sizes

Fig. 7 The verification results for SVM_1 and SVM_2 models

\begin{tabular}{cccccccccc}
\hline \multicolumn{1}{c}{ Mean } & SD & Min. & Max. & Range & \multicolumn{2}{l}{ Mean rank } & $p$ \\
\cline { 6 - 8 } & & & & & & 1000 & 10000 & 5500 & \\
\hline SVM & & & & & & & & & \\
AUC & 0.8166 & 0.0543 & 0.7381 & 0.8927 & 0.1546 & 6.75 & 30.50 & 18.25 & 0.000 \\
ETC & 0.1374 & 0.0278 & 0.1046 & 0.1735 & 0.0761 & 28.50 & 6.50 & 20.50 & 0.000 \\
LR & & & & & & & & & \\
AUC & 0.7759 & 0.0067 & 0.7594 & 0.7828 & 0.0234 & 6.75 & 29.46 & 19.29 & 0.000 \\
ETC & 0.1456 & 0.0023 & 0.1693 & 0.1503 & 0.0078 & 27.38 & 8.42 & 19.71 & 0.000 \\
\hline
\end{tabular}

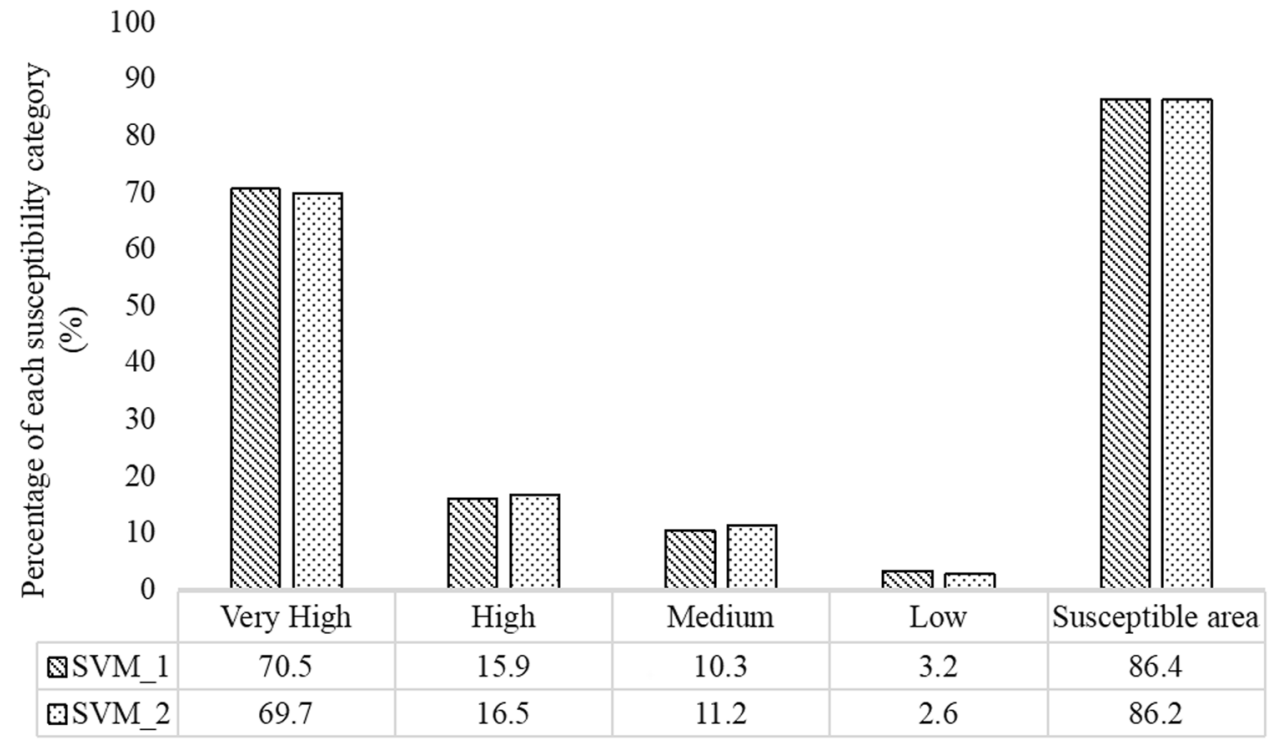


Fig. 8 The LSMs produced by SVM_1 (left) and SVM_2 (right)

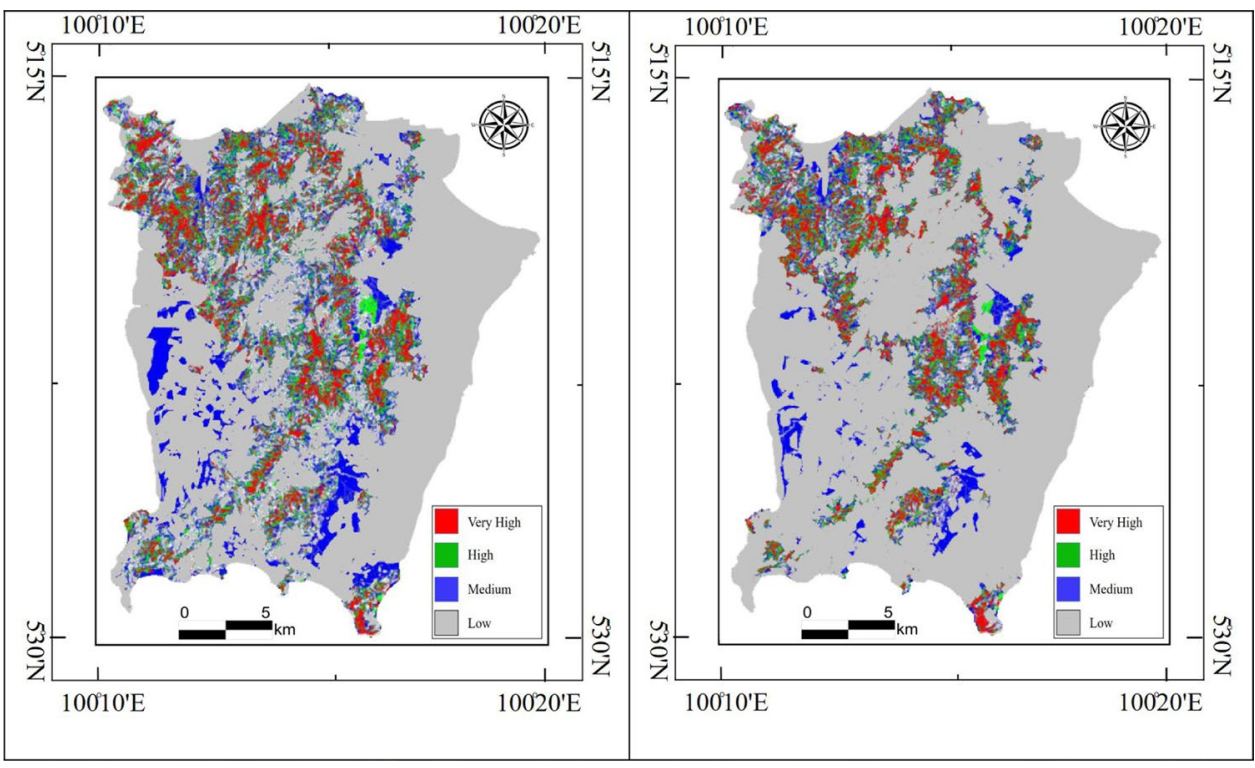

Funding This work was supported by RUI Grant (1001/ PMATHS/8011093) from Universiti Sains Malaysia.

\section{Compliance with ethical standards}

Conflict of interest The authors declare that they have no competing interests.

\section{References}

1. Aditian A, Kubota T, Shinohara Y (2018) Comparison of GISbased landslide susceptibility models using frequency ratio, logistic regression, and artificial neural network in a tertiary region of Ambon, Indonesia. Geomorphology 318:101-111

2. Aghdam IN, Varzandeh MHM, Pradhan B (2016) Landslide susceptibility mapping using an ensemble statistical index (Wi) and adaptive neuro-fuzzy inference system (ANFIS) model at Alborz Mountains (Iran). Environ Earth Sci 75(7):553-572

3. Ahmad F, Yahaya AS, Farooqi MA (2006) Characterization and geotechnical properties of Penang residual soils with emphasis on landslides. Am J Environ Sci 2(4):121-128

4. Akgun A (2012) A comparison of landslide susceptibility maps produced by logistic regression, multi-criteria decision, and likelihood ratio methods: a case study at İzmir, Turkey. Landslides 9(1):93-106

5. Ali MM, Ahmad F, Yahaya AS, Farooqi MA (2011) Characterization and hazard study of two areas of Penang Island, Malaysia. Hum Ecol Risk Assess Int J 17(4):915-922

6. Alkhasawneh MS, Ngah UK, Tay LT, Mat Isa NA, Al-Batah MS (2014) Modeling and testing landslide hazard using decision tree. J Appl Math. https://doi.org/10.1155/2014/929768

7. Ayalew L, Yamagishi H (2005) The application of GIS-based logistic regression for landslide susceptibility mapping in the Kakuda-Yahiko Mountains, Central Japan. Geomorphology 65(1-2):15-31
8. Brenning A (2005) Spatial prediction models for landslide hazards: review, comparison and evaluation. Nat Hazards Earth Syst Sci 5(6):853-862

9. Bui DT, Pradhan B, Lofman O, Revhaug I (2012) Landslide susceptibility assessment in Vietnam using support vector machines, decision tree, and Naive Bayes models. Math Probl Eng. https:// doi.org/10.1155/2012/974638

10. Cervi F, Berti M, Borgatti L, Ronchetti F, Manenti F, Corsini A (2010) Comparing predictive capability of statistical and deterministic methods for landslide susceptibility mapping: a case study in the northern Apennines (Reggio Emilia Province, Italy). Landslides 7(4):433-444

11. Chawla NV, Bowyer KW, Hall LO, Kegelmeyer WP (2002) SMOTE: synthetic minority over-sampling technique. J Artif Intell Res 16:321-357

12. Chen W, Peng J, Hong $H$, Shahabi $H$, Pradhan B, Liu J, Zhu AX et al (2018) Landslide susceptibility modelling using GIS-based machine learning techniques for Chongren County, Jiangxi Province, China. Sci Total Environ 626:1121-1135

13. Cortes C, Vapnik V (1995) Support-vector networks. Mach Learn 20(3):273-297

14. Cox DR (1958) The regression analysis of binary sequences. J R Stat Soc Ser B (Methodol) 20(2):215-232

15. Cruden DM (1991) A simple definition of a landslide. Bull Eng Geol Environ 43(1):27-29

16. Daniel WW (1990) Kruskal-Wallis one-way analysis of variance by ranks. Appl Nonparametr Stat 226-234

17. Drummond C, Holte RC (2006) Cost curves: an improved method for visualizing classifier performance. Mach Learn 65(1):95-130

18. Erener A, Mutlu A, Düzgün HS (2016) A comparative study for landslide susceptibility mapping using GIS-based multi-criteria decision analysis (MCDA), logistic regression (LR) and association rule mining (ARM). Eng Geol 203:45-55

19. Fawcett $T$ (2006) An introduction to ROC analysis. Pattern Recognit Lett 27(8):861-874

20. Frattini P, Crosta G, Carrara A (2010) Techniques for evaluating the performance of landslide susceptibility models. Eng Geol 111(1-4):62-72 
21. Gao H, Fam PS, Low HC, Tay LT, Lateh H (2019) An overview and comparison on recent landslide susceptibility mapping methods. Disaster Adv 12(12):46-64

22. Gao H, Fam PS, Low HC, Tay LT (2020) Logistic regression techniques based on different sample sizes in landslide susceptibility assessment: which performs better? Compusoft 9(4):3624-3628

23. Guzzetti F, Carrara A, Cardinali M, Reichenbach P (1999) Landslide hazard evaluation: a review of current techniques and their application in a multi-scale study, Central Italy. Geomorphology 31(1-4):181-216

24. Haque U, Blum P, Da Silva PF, Andersen P, Pilz J, Chalov SR, Malet JP et al (2016) Fatal landslides in Europe. Landslides 13(6):1545-1554

25. Ho TK (1995) Random decision forests. In: Proceedings of the 3rd international conference on document analysis and recognition: IEEE, pp 278-282

26. Huabin W, Gangjun L, Weiya X, Gonghui W (2005) GIS-based landslide hazard assessment: an overview. Prog Phys Geogr 29(4):548-567

27. Jebur MN, Pradhan B, Tehrany MS (2014) Manifestation of LiDARderived parameters in the spatial prediction of landslides using novel ensemble evidential belief functions and support vector machine models in GIS. IEEE J Sel Top Appl Earth Obs Remote Sens 8(2):674-690

28. Lagomarsino D, Tofani V, Segoni S, Catani F, Casagli N (2017) A tool for classification and regression using random forest methodology: applications to landslide susceptibility mapping and soil thickness modeling. Environ Model Assess 22(3):201-214

29. Lee $S$ (2007) Application and verification of fuzzy algebraic operators to landslide susceptibility mapping. Environ Geol 52(4):615-623

30. Lee S, Pradhan B (2007) Landslide hazard mapping at Selangor, Malaysia using frequency ratio and logistic regression models. Landslides 4(1):33-41

31. Meten M, Bhandary NP, Yatabe R (2015) Application of GIS based fuzzy logic and rock engineering system (RES) approaches for landslide susceptibility mapping in Selelkula area of the Lower Jema River Gorge, Central Ethiopia. Environ Earth Sci 74:3395-3416

32. Micheletti N, Foresti L, Kanevski M, Pedrazzini A, Jaboyedoff M (2011) Landslide susceptibility mapping using adaptive support vector machines and feature selection. In: Geophysical Research Abstracts. EGU, p 13

33. Micheletti N, Kanevski M, Bai S, Wang J, Hong T (2013) Intelligent analysis of landslide data using machine learning algorithms. In: Landslide science and practice. Springer, pp 161-167

34. Mood AM, Graybill FA, Boes DC (1974) Introduction to the theory of statistics, 3rd edn. McGraw-Hill, New York

35. O'Brien RM (2007) A caution regarding rules of thumb for variance inflation factors. Qual Quant 41(5):673-690

36. Oh HJ, Kadavi PR, Lee CW, Lee S (2018) Evaluation of landslide susceptibility mapping by evidential belief function, logistic regression and support vector machine models. Geomat Nat Hazards Risk 9:1053-1070

37. Pal SC, Chowdhuri I (2019) GIS-based spatial prediction of landslide susceptibility using frequency ratio model of Lachung River basin, North Sikkim, India. SN Appl Sci 1(5):416

38. Park S, Choi C, Kim B, Kim J (2013) Landslide susceptibility mapping using frequency ratio, analytic hierarchy process, logistic regression, and artificial neural network methods at the Inje area, Korea. Environ Earth Sci 68(5):1443-1464

39. Petley D (2012) Global patterns of loss of life from landslides. Geology 40(10):927-930

40. Pham BT, Pradhan B, Bui DT, Prakash I, Dholakia M (2016) A comparative study of different machine learning methods for landslide susceptibility assessment: a case study of Uttarakhand area (India). Environ Model Softw 84:240-250

41. Polykretis C, Chalkias C (2018) Comparison and evaluation of landslide susceptibility maps obtained from weight of evidence, logistic regression, and artificial neural network models. Nat Hazards 93(1):249-274

42. Pourghasemi HR, Jirandeh AG, Pradhan B, Xu C, Gokceoglu C (2013) Landslide susceptibility mapping using support vector machine and GIS at the Golestan Province, Iran. J Earth Syst Sci 122(2):349-369

43. Pradhan B (2010) Landslide susceptibility mapping of a catchment area using frequency ratio, fuzzy logic and multivariate logistic regression approaches. J Indian Soc Remote Sens 38(2):301-320

44. Pradhan B, Lee $S$ (2010) Delineation of landslide hazard areas on Penang Island, Malaysia, by using frequency ratio, logistic regression, and artificial neural network models. Environ Earth Sci 60(5):1037-1054

45. Reichenbach P, Rossi M, Malamud BD, Mihir M, Guzzetti F (2018) A review of statistically-based landslide susceptibility models. Earth Sci Rev 180:60-91

46. Segoni S, Pappafico G, Luti T, Catani F (2020) Landslide susceptibility assessment in complex geological settings: Sensitivity to geological information and insights on its parameterization. Landslides. https://doi.org/10.1007/s10346-019-01340-2

47. Shahabi H, Khezri S, Ahmad BB, Hashim M (2014) Landslide susceptibility mapping at central Zab basin, Iran: a comparison between analytical hierarchy process, frequency ratio and logistic regression models. CATENA 115:55-70

48. Süzen ML, Doyuran V (2004) A comparison of the GIS based landslide susceptibility assessment methods: multivariate versus bivariate. Environ Geol 45(5):665-679

49. Tan KH (1994) Engineering properties of granitic sons and rocks of Penang Island, Malaysia. Geol Soc Malaysia 35:69-77

50. Varnes DJ (1978) Slope movement types and processes. Special Report, 17611-33

51. Wang Y, Wu X, Chen Z, Ren F, Feng L, Du Q (2019) Optimizing the predictive ability of machine learning methods for landslide susceptibility mapping using SMOTE for Lishui City in Zhejiang Province, China. Int J Environ Res Public Health 16(3):368-395

52. Weiss GM, Provost $F(2003)$ Learning when training data are costly: the effect of class distribution on tree induction. J Artif Intell Res 19:315-354

53. Xiao T, Segoni S, Chen L, Yin K, Casagli N (2020) A step beyond landslide susceptibility maps: a simple method to investigate and explain the different outcomes obtained by different approaches. Landslides 17(3):627-640

54. Yao X, Tham L, Dai F (2008) Landslide susceptibility mapping based on support vector machine: a case study on natural slopes of Hong Kong, China. Geomorphology 101(4):572-582

55. Zare M, Pourghasemi HR, Vafakhah M, Pradhan B (2013) Landslide susceptibility mapping at Vaz Watershed (Iran) using an artificial neural network model: a comparison between multilayer perceptron (MLP) and radial basic function (RBF) algorithms. Arab J Geosci 6:2873-2888

56. Zhou ZH (2016) Machine learning. Tsinghua University Press, Beijing (Chinese)

Publisher's Note Springer Nature remains neutral with regard to jurisdictional claims in published maps and institutional affiliations. 